Research Paper

\title{
A comprehensive transcriptomic analysis of alternate interferon signaling pathways in peripheral blood mononuclear cells in rheumatoid arthritis
}

\author{
Liang $\mathrm{Han}^{1,{ }^{*}}$, Shenghao Tu ${ }^{1,}{ }^{*}$, Pan Shen ${ }^{1}$, Jiahui Yan ${ }^{1}$, Yao Huang ${ }^{1}$, Xin Ba ${ }^{1}$, Tingting Li ${ }^{1}$, Weiji Lin ${ }^{1}$, \\ Huihui $\mathrm{Li}^{2}$, Kun $\mathrm{Yu}^{2}$, Jing Guo ${ }^{3}$, Ying Huang ${ }^{1}$, Kai Qin ${ }^{1}$, Yu Wang ${ }^{1}$, Zhe Chen ${ }^{1}$ \\ ${ }^{1}$ Department of Integrated Traditional Chinese and Western Medicine, Tongji Hospital of Tongji Medical College of \\ Huazhong University of Science and Technology, Wuhan 430030, China \\ ${ }^{2}$ Department of Cardiology, Tongji Hospital of Tongji Medical College of Huazhong University of Science and \\ Technology, Wuhan 430030, China \\ ${ }^{3}$ Wuhan Institute of Biotechnology, Wuhan Biobank, Wuhan 430000, China \\ *Equal contribution
}

Correspondence to: Zhe Chen; email: zhepi2006@163.com, https://orcid.org/0000-0002-8654-9218

Keywords: rheumatoid arthritis (RA), type I interferon, interferon- $\gamma$ (IFN- $\gamma$ ), single-cell sequencing (SCS), peripheral blood mononuclear cells (PBMCs)

Received: May 18, 2021

Accepted: August 3, 2021

Published: August 25, 2021

Copyright: (C) 2021 Han et al. This is an open access article distributed under the terms of the Creative Commons Attribution License (CC BY 3.0), which permits unrestricted use, distribution, and reproduction in any medium, provided the original author and source are credited.

\section{ABSTRACT}

Interferon (IFN) signaling pathways play crucial roles in the pathogenesis of rheumatoid arthritis (RA). Prior studies have mainly studied mixed alterations in the IFN signaling pathway in RA, but these studies have not been sufficient to elucidate how imbalanced IFN signaling subtly influences immune cells. Single-cell RNA (scRNA) sequencing makes it possible to better understand the alternations in the interferon signaling pathways in RA. In the present study, we found that IFN signaling pathways were activated in natural killer (NK) cells, monocytes, T cells, B cells, and most immune cell subclasses in RA. We then explored and analyzed the connections between abnormal IFN signaling pathways and cellular functional changes in RA. Single-Cell rEgulatory Network Inference and Clustering (SCENIC) analysis and gene regulatory network (GRN) construction were also performed to identify key transcription factors in RA. Finally, we also investigated altered IFN signaling pathways in multiple RA peripheral blood samples, which indicated that abnormal IFN signaling pathways were universally observed in RA. Our study contributes to a better understanding of the delicate and precise regulation of IFN signaling in the immune system in RA. Furthermore, common alternations in IFN signaling pathway-related transcription factors could help to identify novel therapeutic targets for RA treatment.

\section{INTRODUCTION}

Rheumatoid arthritis (RA) is a systemic, chronic, incurable autoimmune inflammatory disease affecting approximately $0.5 \%-1 \%$ of the world population [1]. Imbalanced immune responses both in circulating peripheral blood and in diseased joint cavities are closely related to the occurrence and development of RA [2]. It has been repeatedly illustrated that aberrant $\mathrm{CD}^{+}$helper $\mathrm{T}(\mathrm{Th})$ cells produce proinflammatory cytokines, and abnormally activated $\mathrm{B}$ cells can differentiate into plasma cells that ultimately produce a large panel of autoantibodies [3, 4]. In addition, aberrant alterations of innate immune cells such as monocytes, macrophages, and natural killer (NK) cells, as well as dendritic cells (DCs), are also related to RA [5-7]. Interferons (IFNs) are a family of cytokines produced by various cells that play pivotal roles in early defense against viral infection in mammals [8, 9]. Moreover, as important immunomodulators, IFNs also 
impressively affect several immunity responses [10]. Both abnormal levels of IFNs and alterations in IFN signaling pathways have been observed in RA, systemic lupus erythematosus (SLE), primary Sjögren syndrome (pSS), and other autoimmune diseases [11-13]. However, the specific mechanisms of IFN signaling pathways in RA are poorly understood.

Although the etiology and pathogenesis of RA are still not fully understood, it has been demonstrated that IFNand IFN-related signaling pathways partly promote the inflammatory response in RA patients [13]. Human IFN can be broadly grouped into three main classes: type I IFN, type II IFN, and type III IFN [14]. type I IFNs consists of IFN- $\alpha$, IFN- $\beta$, IFN- $\varepsilon$, IFN- $\kappa$, and IFN- $\omega$, and type II IFNs consists of only IFN- $\gamma$ [15]. Type III IFN was discovered approximately two decades ago and includes IFN- $\lambda 1$, IFN- $\lambda 2$, IFN- $\lambda 3$ as well as IFN- $\lambda 4$ [16]. In our study, we primarily discuss type I IFN (IFN- $\alpha$ and IFN- $\beta$ ) and type II IFN due to their important roles in RA.

Individual case reports showed that patients were diagnosed with RA after using IFN- $\alpha$ to treat other diseases $[17,18]$. Previous studies have also reported that type I IFN response genes are potential biomarkers for predicting the development of RA [11, 19]. The relationship between IFNs and RA is not only restricted to high clinical relevance but is also reflected in many molecular biology studies. IFN- $\alpha$ increases the production of proinflammatory cytokines such as interleukin (IL)- $1 \beta$ and IL-18 in synovial cells [20]. In contrast, IFN- $\beta$ inhibits expression of IL-1 $\beta$ and tumor necrosis factor (TNF) in peripheral blood mononuclear cells (PBMCs) [21]. Moreover, IFN- $\beta$-treated collagen-induced arthritis (CIA) mice exhibited relieved arthritis, suggesting that IFN- $\beta$ exerts potential therapeutic effects [22]. Beyond expectation, randomized clinical research on the treatment of RA using recombinant IFN- $\beta$ negated the therapeutic effects of IFN- $\beta$ in RA [23]. Thus, the effects of IFNs and their response genes and pathways in RA deserve further investigation.

In the past decade, the evolution of high-throughput technologies have made it possible to detect the expression of tens of thousands of genes in one sample at the same time, giving us novel insights into the pathogenesis of RA [24]. Nevertheless, the technologies and analytic tools of single-cell RNA (scRNA) sequencing are rapidly expanding and maturing $[25,26]$. Researchers are able to understand the mechanisms of RA in parallel to the dimensions of cell and gene expression with the development of scRNA sequencing [26, 27]. In the present study, we comprehensively analyzed the discrepancies between RA and healthy controls in the terms of both scRNA transcriptomics and conventional RNA transcriptomics of PBMCs. Alterations in type I IFN and IFNs and their response genes and pathways, as well as the resulting potential impacts on the function of immune cells are discussed in detail.

\section{RESULTS}

\section{Four primary immune cell classes were identified by scRNA transcriptome analysis}

To comprehensively explore the disorders in PBMCs from RA, scRNA sequencing data were preprocessed, and batch effects were removed (Supplementary Figure 1A-1D). All cells were grouped to produce 27 clusters first, and all cells were visualized using the principal component analysis (PCA)-based uniform manifold approximation and projection (UMAP) method (Figure 1B). Highly expressed marker genes in each cluster were calculated, and violin plots were used to illustrate the expression of several widely used marker genes in each cluster (Figure 1C).

In the present study, NK cells, monocytes, and $\mathrm{T}$ and $\mathrm{B}$ cells were identified (Figure 1D), and these cells were conserved for further analysis. Although plasmacytoid DCs (pDCs) and myeloid DCs (mDCs) were also distinguished (Figure 1D), the number of cells was too small to analyze $(466 \mathrm{mDCs}, 72 \mathrm{pDCs}$, and 42 megakaryocytes), so those cells were filtered out in subsequent experiments. Moreover, the marker genes of cluster 18 and cluster 19 did not support them as any common or specific cell types in PBMCs, so they were considered as mixed cells (Figure 1D). Considering that clusters 18 and 19 had few cells (the number of all cells in the two clusters was no more than 300), these two clusters were also abandoned.

\section{Altered IFN-stimulated signaling pathways and genes in NK cells, monocytes, $T$ cells, and $B$ cells from RA PBMCs}

Gene set enrichment analysis (GSEA) of NK cells, monocytes, $\mathrm{T}$ cells, and $\mathrm{B}$ cells was performed to reveal the differences between RA and healthy controls (HCs), and the GSEA results indicated the widespread dysregulation of immune cells in peripheral blood from the RA patient (Figure 2A-2D). Among all significant gene sets, it was not difficult to observe that the Gene Ontology (GO) biological process (BP) pathway named "RESPONSE TO TYPE I INTERFERON" was upregulated in $\mathrm{NK}$ cells, monocytes, $\mathrm{T}$ and $\mathrm{B}$ cells from RA sample (Figure 2E-2H). Moreover, three other gene sets named "RESPONSE_TO_INTERFERON ALPHA", "RESPONSE_TO_INTERFERON_BETA", and "RESPONSE_TO_INTERFERON_GAMMA" were 
A

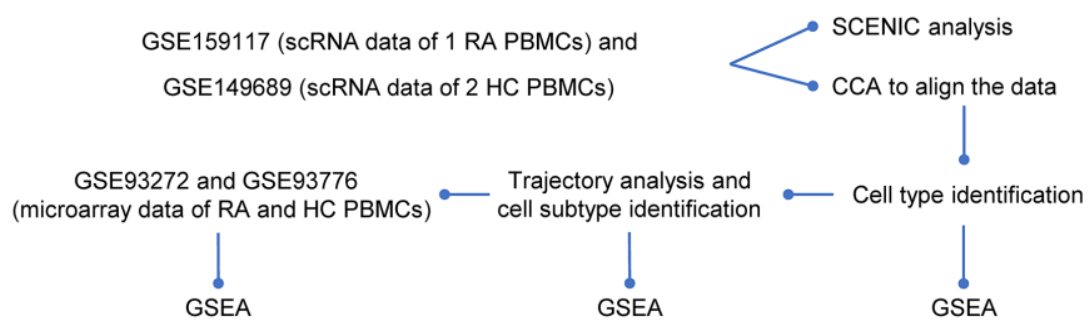

B

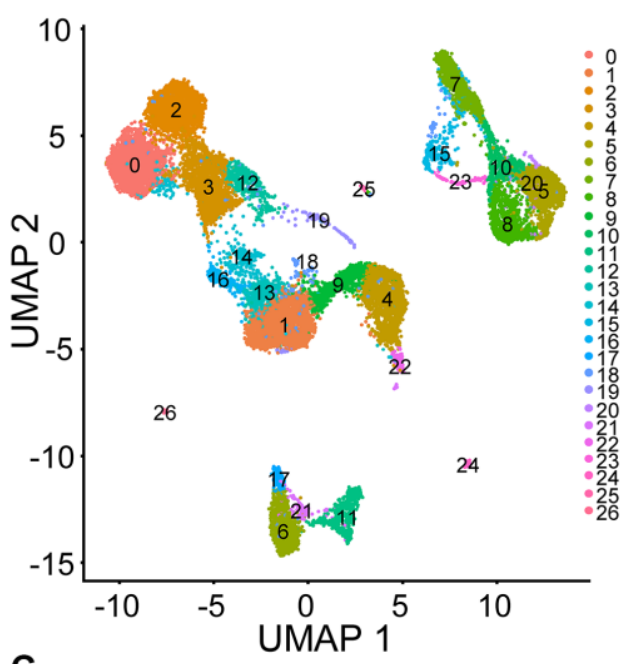

D

\begin{tabular}{|c|c|c|}
\hline Cluster & Gene & Cell type \\
\hline $0-3,12-14,16$ & $C D 3 D$ & $\mathrm{~T}$ cells \\
\hline $4,9,22$ & KLRF1 & $\begin{array}{l}\text { Natural killer } \\
\text { cells }\end{array}$ \\
\hline $6,11,17,21,26$ & CD79A & B cells \\
\hline $5,7,8,10,20$ & CD68 & Monocytes \\
\hline 24 & LILRA4 & $\begin{array}{l}\text { Plasmacytoid } \\
\text { dendritic cells }\end{array}$ \\
\hline 15,23 & $C D 1 C$ & $\begin{array}{c}\text { Myeloid } \\
\text { dendritic cells }\end{array}$ \\
\hline 25 & TUBB1 & Megakaryocytes \\
\hline 18-19 & - & Mixed cells \\
\hline
\end{tabular}

C

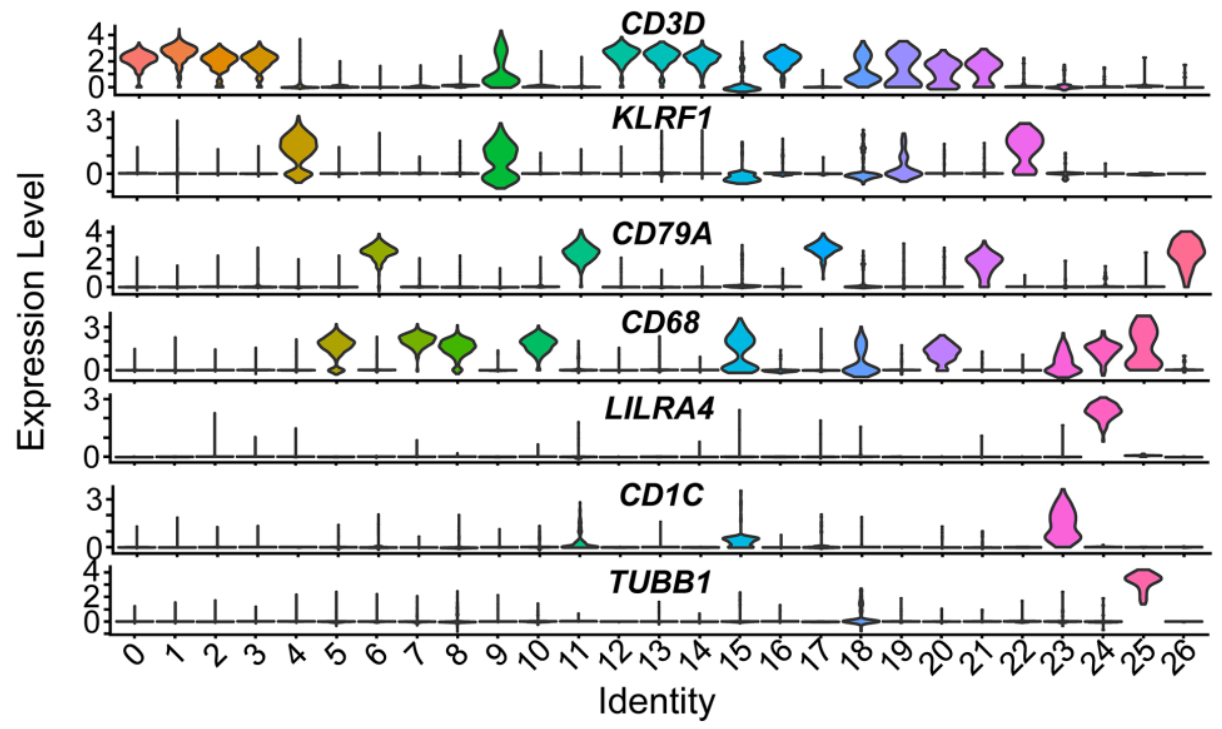

Figure 1. Study design and preliminary analysis. (A) Workflow of scRNA sequencing and microarray data analysis. Step 1: We first downloaded individual rheumatoid arthritis (RA) and healthy control (HC) peripheral blood mononuclear cell (PBMC) scRNA sequencing data (GSE159117 and GSE149689) from the Gene Expression Omnibus (GEO) database (https://www.ncbi.nlm.nih.gov/geo/). To eliminate the potential batch effects, canonical correlation analysis (CCA) was performed to integrate the two datasets. Afterwards, four main immune cell types ( $T$ cells, B cells, NK cells and monocytes) in PBMCs were identified. Then, we explored the up- and downregulated genes and gene sets using differential gene expression analysis and gene set enrichment analysis (GSEA). Subsequently, four main immune cell subtypes were identified using Monocle2, and up- and downregulated interferon (IFN)-related genes and gene sets in different immune cell subtypes were also identified. Step 2: Key transcription factors were identified, and gene regulatory networks (GRNs) were constructed using Single-Cell rEgulatory Network Inference and Clustering (SCENIC) analysis. Step 3: We downloaded microarray datasets including multiple RA and HC PBMC samples and explored the up- and downregulated IFN-related genes and gene sets. (B) Two-dimensional uniform manifold approximation and projection (UMAP) visualization of cell clusters. Cells were colored by clusters. (C) Violin plots of selected marker genes to identify cell classifications and their expression levels in each cell cluster. (D) The table of correspondence between cell clusters and cell types. 


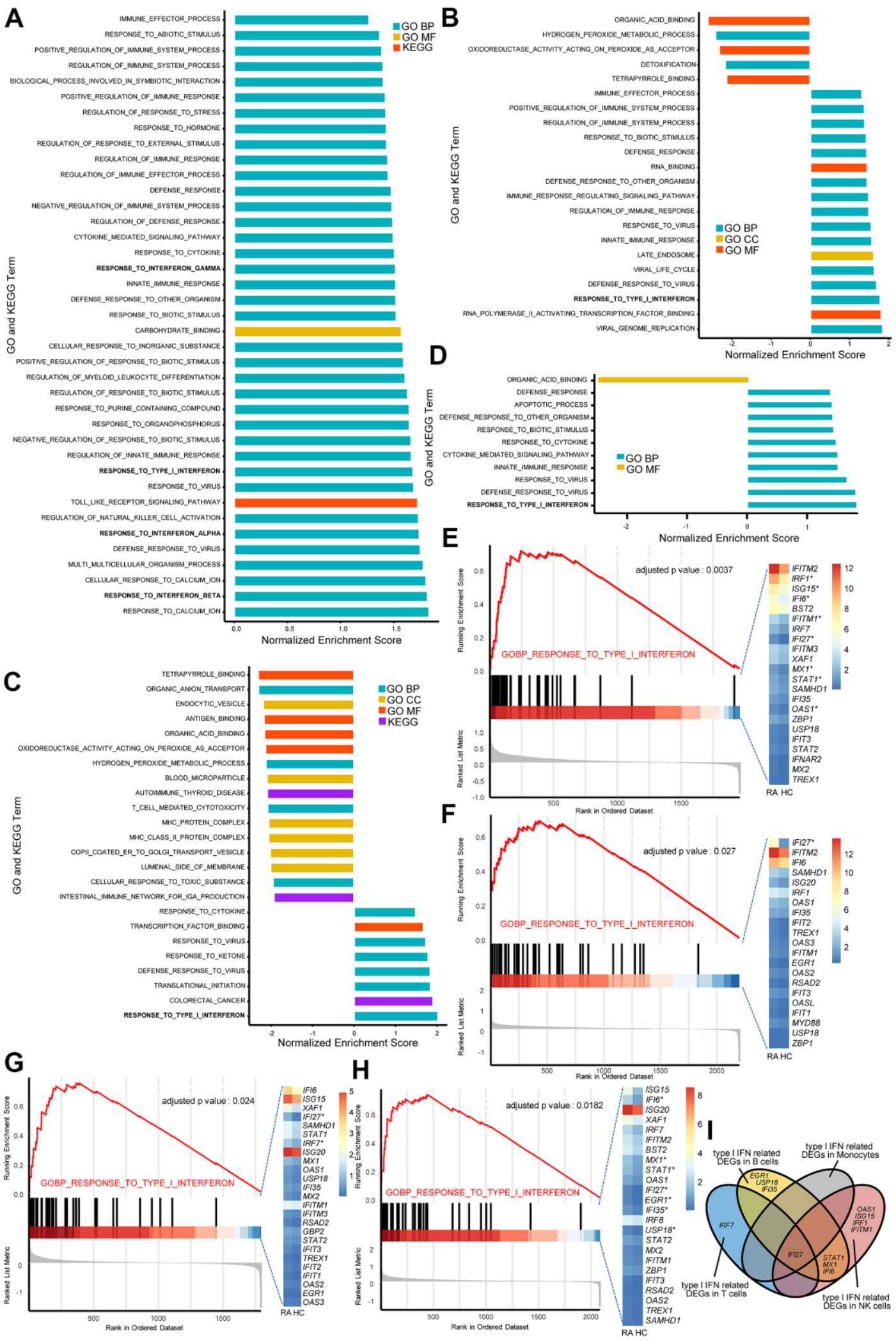

Figure 2. The type I interferon (IFN) signaling pathway is activated in natural killer (NK) cells, monocytes, and T and B cells in rheumatoid arthritis (RA). All GSEA bar plots of NK cells (A), monocytes (B), T cells (C) and B cells (D) detected by single-cell RNA (scRNA) sequencing data. GSEA plots and Het maps showing the activated type I IFN signaling pathway and genes in NK cells (E), monocytes (F), T cells (G) and $B$ cells $(\mathbf{H})$ detected by scRNA sequencing data. Upregulated genes in RA are marked with an asterisk $\left({ }^{*}\right)$. All upregulated genes satisfied log2 (fold change) $>0.25$ and adjusted p-value $<0.05$. (I) Venn diagram of upregulated type I IFN-stimulated genes in each immune cell type. 
also activated in NK cells from the RA patient (Figure 2A).

The above results indicate that IFN- $\alpha-$, and IFN- $\beta$ stimulated genes are comprehensively activated in RA peripheral blood. IFN- $\gamma$-stimulated genes are also upregulated in RA NK cells. Moreover, there were differentially upregulated IFN-stimulated genes in NK cells, monocytes, T cells, and B cells from RA (Figure 2I), indicating that there were different alterations influenced by IFN in distinct immune cell types. Therefore, we further analyzed the alterations of IFN- $\alpha$ , IFN- $\beta-$, and IFN- $\gamma$-stimulated genes in NK cells, monocytes, T cells, and B cells from the RA patient.

\section{Alterations and influence of IFN stimulated pathways in RA NK cells}

To better explore the impacts of IFN-stimulated genes and signaling pathways in NKs from RA, we reclustered NK cells and divided them into three subclusters: activated $\mathrm{CD}^{\mathrm{dim}}{ }^{\mathrm{dim}} \mathrm{NK}$ cells, inactivated CD56 ${ }^{\mathrm{dim}} \mathrm{NK}$ cells and CD56 ${ }^{\text {bright }}$ NK cells (Figure 3A, 3B). We then examined the transcriptional changes associated with RA in these three NK subclusters using GSEA. The GSEA results showed that IFN- $\gamma$ stimulated signaling pathways in the three NK subclusters were all activated (Figure 3C). Moreover, type I IFN stimulated signaling pathways were activated in activated CD56 $6^{\text {bright }}$ NK cells and activated CD56 $^{\text {dim }}$ NK cells (Figure 3C). We also calculated differentially expressed genes (DEGs) in the three NK cell subclusters between the RA patient and $\mathrm{HCs}$, and the results showed that some type I IFN- and IFN- $\gamma$ stimulated genes, such as STAT1 and SOCS1, were significantly upregulated in NK cell subclusters (Figure 3D-3G). The above results all indicate that IFNs are partially implicated in NK cell regulation, which eventually causes abnormal changes in the immune environment in peripheral blood. In addition, it is interesting that CD56 ${ }^{\mathrm{dim}} \mathrm{NK}$ cells might produce more IFN- $\gamma$ according to the results of differential gene expression analysis (Figure 3F), even though CD56 ${ }^{\mathrm{dim}} \mathrm{NK}$ cells primarily exert cytotoxic effects in PBMCs.

We also examined functional changes in NK subclusters in RA, and the inactivated CD56 ${ }^{\mathrm{dim}} \mathrm{NK}$ cells in RA exhibited lower activity in the Kyoto Encyclopedia of Genes and Genomes (KEGG) pathway of "KEGG_NATURAL_KILLER_CELL_MEDIATED_C

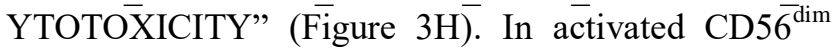
NK cells, expression of the cytotoxic effector molecules PRF1 and GZMB was also significantly depressed (Figure 3I). These results indicate that the cytotoxic capacity of $\mathrm{CD}_{5} 6^{\mathrm{dim}} \mathrm{NK}$ cells is reduced in RA. Importantly, it is reasonable to believe that those functional changes in RA NK cells are partly associated with the activation of IFN-stimulated genes and pathways based on previous studies [28].

\section{Alterations and influence of IFN-stimulated pathways in RA monocytes}

In PBMCs, monocytes are commonly divided into $\mathrm{CD} 14^{++} \mathrm{CD} 16^{-}$(classical), $\mathrm{CD} 14^{++} \mathrm{CD} 16^{+}$(intermediate), and $\mathrm{CD} 14^{-} \mathrm{CD} 16^{++}$(nonclassical) populations according to their developmental processes [29]. Here, we followed a similar classification and monocytes were split into $\mathrm{CD} 14^{+}$and $\mathrm{CD} 16^{+}$monocytes using single-cell trajectory analysis (Figure 4A, 4B). We then analyzed the activity of IFN-stimulated pathways by performing GSEA. CD14 ${ }^{+}$ and $\mathrm{CD} 16^{+}$monocytes were all activated by type I IFN (Figure 4C, 4D), and CD14 ${ }^{+}$monocytes were activated by IFN- $\gamma$ simultaneously (Figure 4C, 4E).

$\mathrm{CD} 14^{+}$monocytes are more inclined to migrate to local tissues with high levels of $C D 62 L$, and chemokines $(C X C R 2, C C R 2)$, and $\mathrm{CD}_{14}{ }^{+}$monocytes are also considered osteoclast precursors [29-31]. In our study, high HLA-DRB5 expression was also observed in $\mathrm{CD}_{14}{ }^{+}$monocytes from the RA patient (Figure 4E), indicating an inflamed and erosive osteoclast phenotype in RA joint cavities. In contrast, $\mathrm{CD} 16^{+}$monocytes primarily secreted inflammatory factors in PBMCs [5]. We also found that $\mathrm{CD} 16^{+}$monocytes from RA patients expressed significantly more $\mathrm{CH} 25 \mathrm{H}$ (Figure 4D), which could promote the inflammatory response in RA peripheral blood [32]. We propose that these inflammatory changes are caused by IFN's influence according to prior studies [33].

\section{Alterations and influence of IFN stimulated pathways in $\mathrm{RA} \mathrm{CD4}^{+}$and $\mathrm{CD8}^{+} \mathrm{T}$ cells}

The heterogeneous nature of $\mathrm{T}$ cells makes investigation of $\mathrm{T}$ cells complex. For convenience, $\mathrm{T}$ cells were split into three subgroups: $\mathrm{CD} 4^{+} \mathrm{T}$ cells, $\mathrm{CD} 8^{+} \mathrm{T}$ cells, and naïve $\mathrm{T}$ cells via single-cell trajectory analysis (Figure 5A, 5B). GSEA indicated that type I IFN- and IFN- $\gamma$ stimulated pathways were activated in $\mathrm{CD} 4^{+} \mathrm{T}$ cells and $\mathrm{CD}^{+} \mathrm{T}$ cells but not in naïve $\mathrm{T}$ cells (Figure 5C). Meanwhile, expression of IFN-stimulated genes such as IRF7 was significantly increased in $\mathrm{CD}^{+} \mathrm{T}$ cells and $\mathrm{CD}^{+} \mathrm{T}$ cells from the RA patient (Figure $5 \mathrm{D}, 5 \mathrm{E}$ ). In addition, levels of GZMH were increased in RA CD8 ${ }^{+}$ $\mathrm{T}$ cells (Figure 5E), which might also be caused by type I IFN activation [34].

\section{Alterations and influence of IFN stimulated pathways in RA naïve $B$ cells and plasma cells}

For B cells, cell trajectory analysis was performed, and the track plot of B cell trajectories is shown in 
A

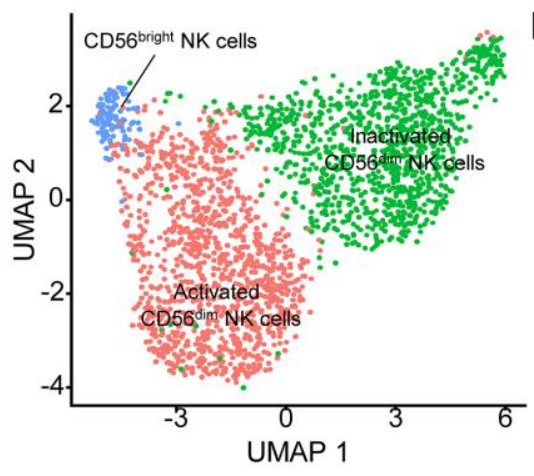

B

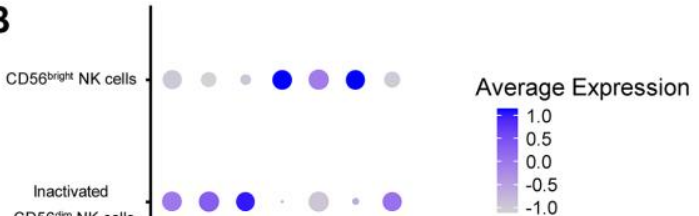

CD56 $6^{\text {sm }} \mathrm{NK}$ ce

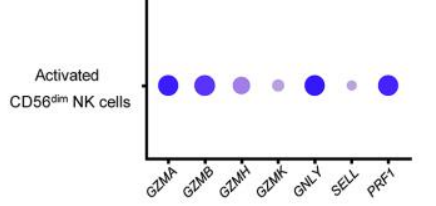

Percent Expressed

- 25

- 50
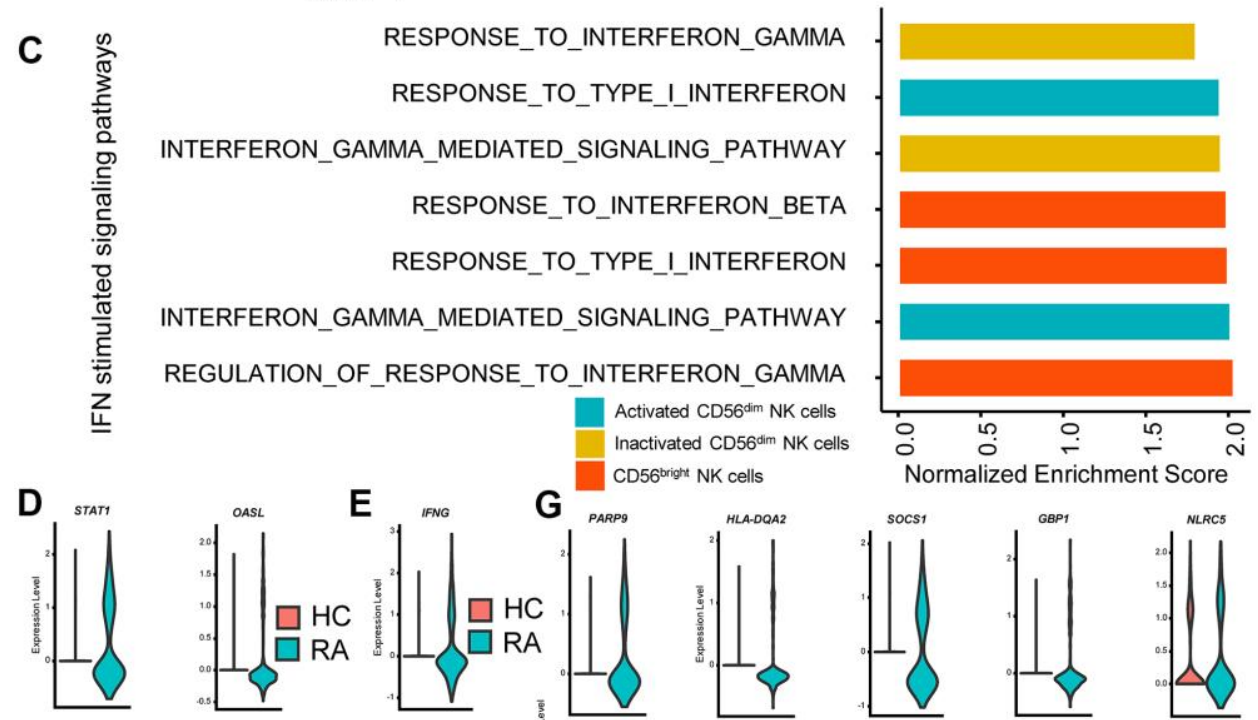

$\mathbf{G}$

CD56 bright NK cells

$\mathbf{F}$

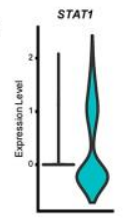

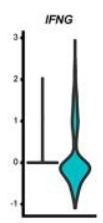
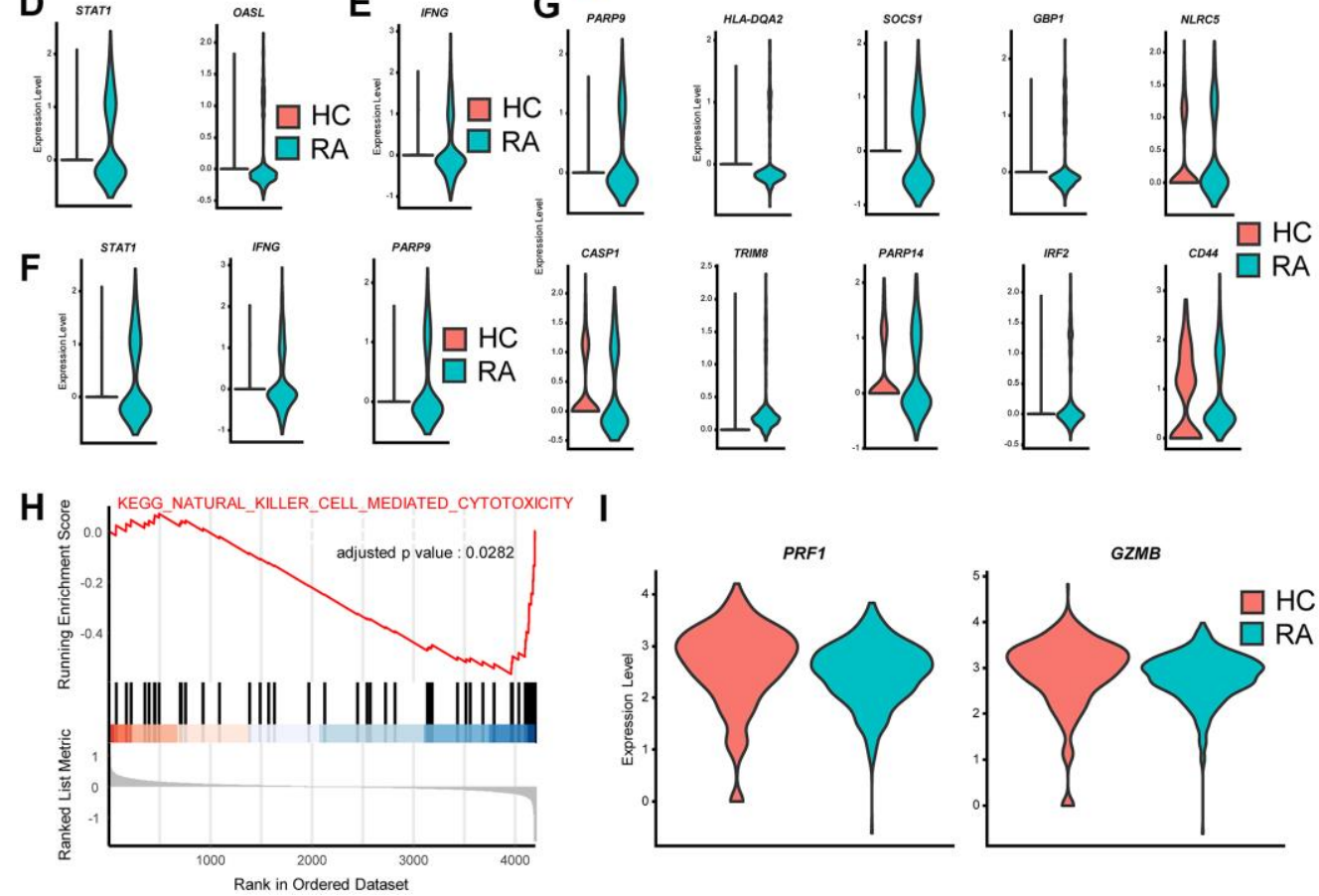

Figure 3. Interferon (IFN)-stimulated pathways promote cytokine secretion and inhibit cytotoxicity in rheumatoid arthritis (RA) natural killer (NK) cells. (A) Two-dimensional uniform manifold approximation and projection (UMAP) visualization of reclustered NK cells. Three NK cell clusters (activated CD56 $6^{\text {dim }}$ NK cells, inactivated CD56 ${ }^{\text {dim }}$ NK cells and CD56 bright $N K$ cells) were identified. (B) Dot plot illustrating the expression levels of several marker genes in three NK cell subtypes. (C) Bar plots of selected gene set enrichment analysis (GSEA) results indicated altered IFN signaling pathways in three NK cell subtypes. (D) Violin plots of significantly upregulated type I IFNstimulated genes in RA-activated CD56 $6^{\text {dim }}$ NK cells (STAT1) and in RA CD56 ${ }^{\text {bright }}$ NK cells (OASL). (E) Violin plot of significantly upregulated IFN$\gamma$-stimulated genes in RA CD56 $6^{\text {bright }}$ NK cells. (F) Violin plots of significantly upregulated IFN- $\gamma$-stimulated genes in RA-activated CD56 ${ }^{\text {dim }}$ NK cells. (G) Violin plots of significantly upregulated IFN- $\gamma$-stimulated genes in RA-inactivated CD56 dim NK cells. (H) GSEA plot of the "KEGG_NATURAL_KILLER_CELL_MEDIATED_CYTOTOXICITY" pathway in RA inactivated CD56 dim NK cells. (I) Violin plots of significantly upregulated cytotoxic effector genes in RA activated $\operatorname{CD} 56^{\text {dim }}$ NK cells. All upregulated genes satisfied $\log 2$ (fold change) $>0.25$ and adjusted pvalue $<0.05$ 
Figure 6A. Three B cell clusters included naïve B cells, plasma cells, and memory B cells according to their marker genes (Figure 6B). GSEA results showed that type I IFN and IFN- $\gamma$ primarily affected naïve B cells (Figure 6C), and upregulated type I IFNstimulated genes were also observed in RA naïve $\mathrm{B}$ cells (Figure 6D). Moreover, GSEA results indicated that naïve $\mathrm{B}$ cells were one of the sources of type I IFN (Figure 6C).

Remarkably, the GSEA results showed that naïve B cells from RA were activated and tended to proliferate faster (Figure 6E). EGRl has been demonstrated to promote $\mathrm{B}$ cell differentiation into plasma cells and support antibody secretion, and higher expression of EGRl was identified in naïve B cells from RA (Figure 6D) [35]. The pseudotimes of B cells were also significantly different between the two groups, and RA plasma cells exhibited older pseudotimes (Figure 6F), indicating that RA B cells are primarily concentrated at the end of the differentiation trajectory. Moreover, the proportions of three $\mathrm{B}$ cell types in $\mathrm{RA}$ and $\mathrm{HC}$ were compared, and the results revealed that the number of plasma cells in RA was increased with the same proportion of naïve B cells (Figure 6G). In addition, GSEA results demonstrated that naïve $B$ cells from RA tended to produce more of the proinflammatory factors IL- $1 \beta$ and IL-12 (Figure 6E).
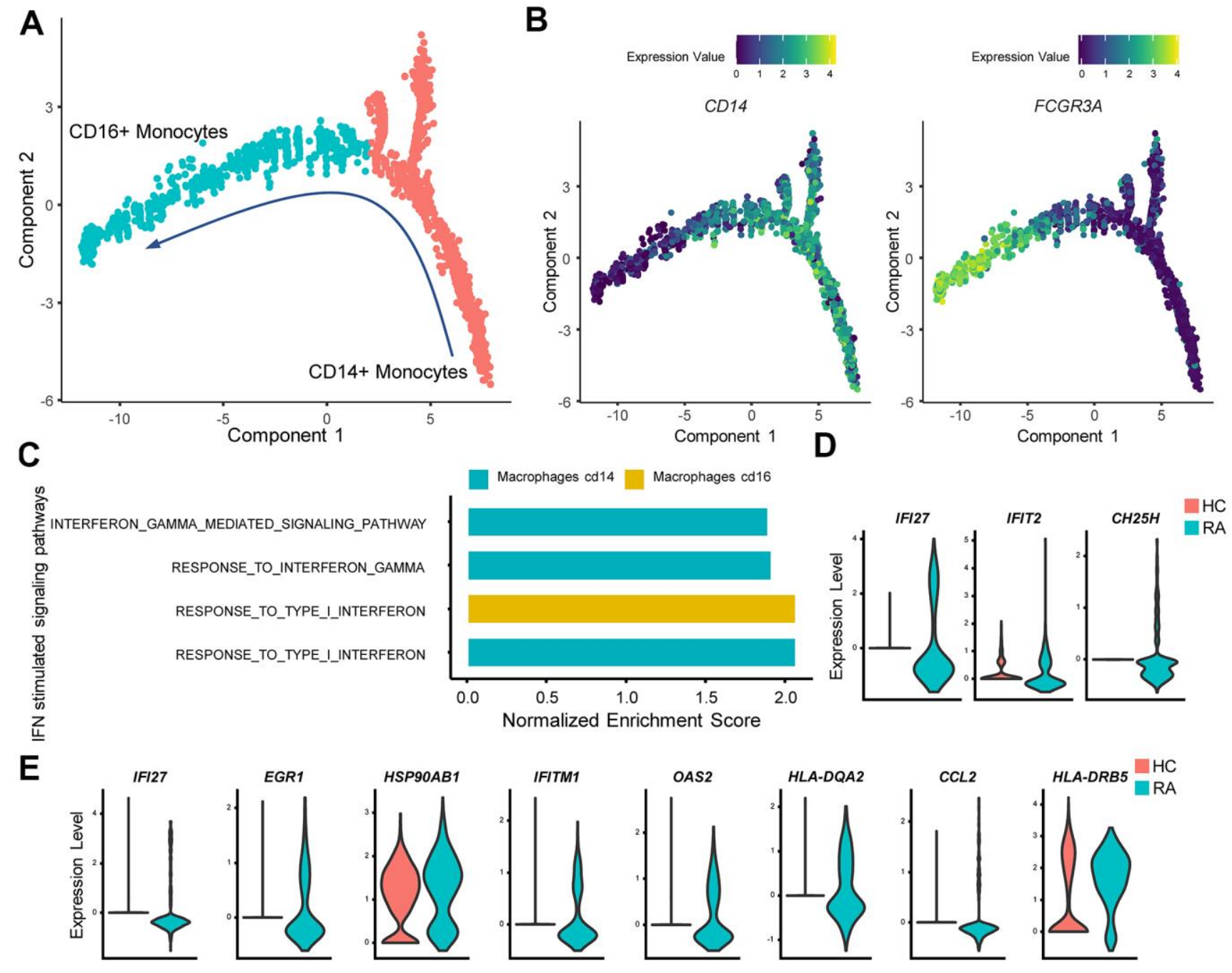

Figure 4. IFN promotes rheumatoid arthritis (RA) monocyte inflammatory responses. (A) Red and cyan points indicate CD14 ${ }^{+}$ monocytes and $\mathrm{CD}_{16}{ }^{+}$monocytes, respectively. The direction of arrows indicates the direction of the pseudotime. (B) Trajectory plots of monocytes indicating the expression levels of CD14 and FCGR3A (CD16a) in monocytes. (C) Bar plots of selected gene set enrichment analysis (GSEA) results indicate activated IFN signaling pathways in $\mathrm{CD} 14^{+}$and $\mathrm{CD} 16^{+}$monocytes. (D) Violin plots of significantly upregulated type I IFN-stimulated genes (IFI27, IFIT2) and upregulated proinflammatory gene $(\mathrm{CH} 25 \mathrm{H})$ in RA $\mathrm{CD}_{16}^{+}$monocytes. (E) Violin plots of significantly upregulated IFN- $\gamma$-stimulated genes (IFI27, EGR1, HSP9OAB1, IFITM1, OAS2, HLA-DQA2, CCL2) and upregulated proinflammatory genes (HLA$D R B 5$ ) in RA CD14 ${ }^{+}$monocytes. All upregulated genes satisfied log2 (fold change) $>0.25$ and adjusted $p$ value $<0.05$. 
Interestingly, plasma cells in RA exhibited lower activity in the "RESPONSE TO INTERFERON GAMMA" pathway (Figure $6 \mathrm{H}$ ), and the expression of IFN- $\gamma$ stimulated genes, such as IFITM3 and IFI30, were downregulated in RA plasma cells (Figure 6I). In accordance with previous studies, this might affect antibody class switching in RA plasma cells [36].

Single-cell regulatory network inference and clustering (SCENIC) analysis revealed the chief transcription factors and gene regulatory networks (GRNs) in RA PBMCs

The effects of IFNs on immune cells are complex. Here, we focused on the regulation of downstream transcription factors and their target genes by IFNs. We first calculated and compared the AUC values of the regulon between RA and $\mathrm{HC}$, and significantly differential regulons are illustrated in Figure 7A.
Regulons of IRF7_127g, STAT1_115g, STAT2_49g and STAT2_extended_101g were significantly upregulated in most cell types. Instead, the regulons of IRF1_14g and UQCRB_19g were significantly decreased in most cell types (Figure 7A). Subsequently, we constructed GRNs in different immune cell types. Many IFN-stimulated genes were included in the GRNs (Figure 7B), and different cell types exhibited diverse IFN-stimulated genes, indicating different and fine regulation of gene expression in distinct immune cells.

External datasets validated the activation of interferon-simulated pathways and genes in peripheral blood from RA patients

Considering that the above results came from a single RA patient, we used external transcriptomic data from multiple individuals to explore the expression of IFN-
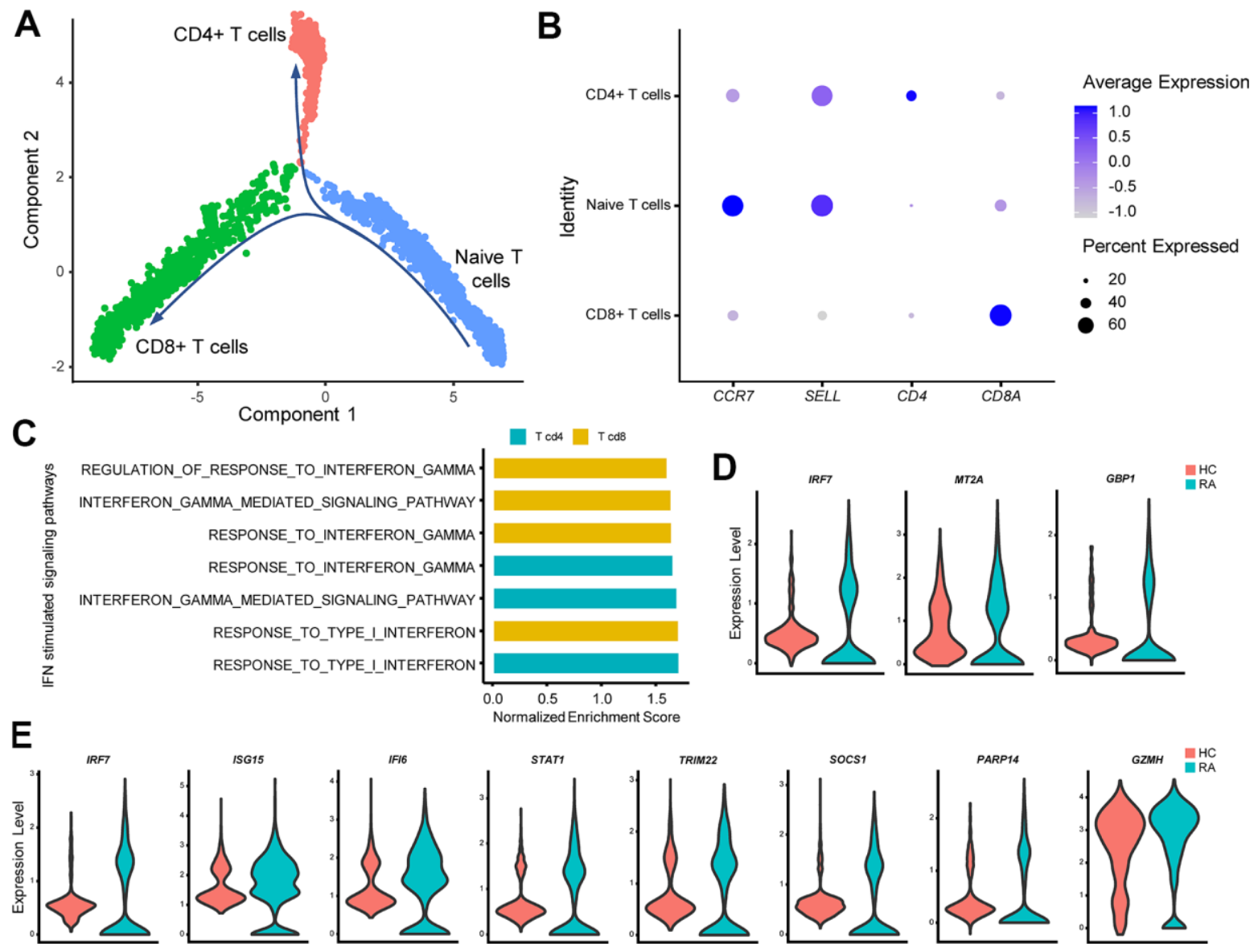

Figure 5. IFN promotes rheumatoid arthritis (RA) CD4 ${ }^{+}$Th1 polarization and increases RA CD8+ T cell cytotoxicity. (A) Trajectory plots of T cells from RA and healthy control individuals ( $\mathrm{HC}$ ). The direction of arrows indicates the direction of the pseudotime. (B) Dot plot illustrating the expression levels of several marker genes in three T cell subtypes. (C) Bar plots of selected gene set enrichment analysis (GSEA) results indicate activated IFN signaling pathways in $\mathrm{CD} 4^{+}$and $\mathrm{CD} 8^{+} \mathrm{T}$ cells. (D) Violin plots of significantly upregulated IFN- $\gamma$-stimulated genes in RA $\mathrm{CD}^{+} \mathrm{T}$ cells. (E) Violin plots of significantly upregulated IFN- $\gamma$-stimulated genes (IRF7, ISG15, IFI6, STAT1, TRIM22, SOCS1, PARP14) and the cytotoxic effector gene (GZMH) in RA CD8 ${ }^{+}$T cells. All upregulated genes satisfied log2 (fold change) $>0.25$ and adjusted $p$-value $<0.05$. 


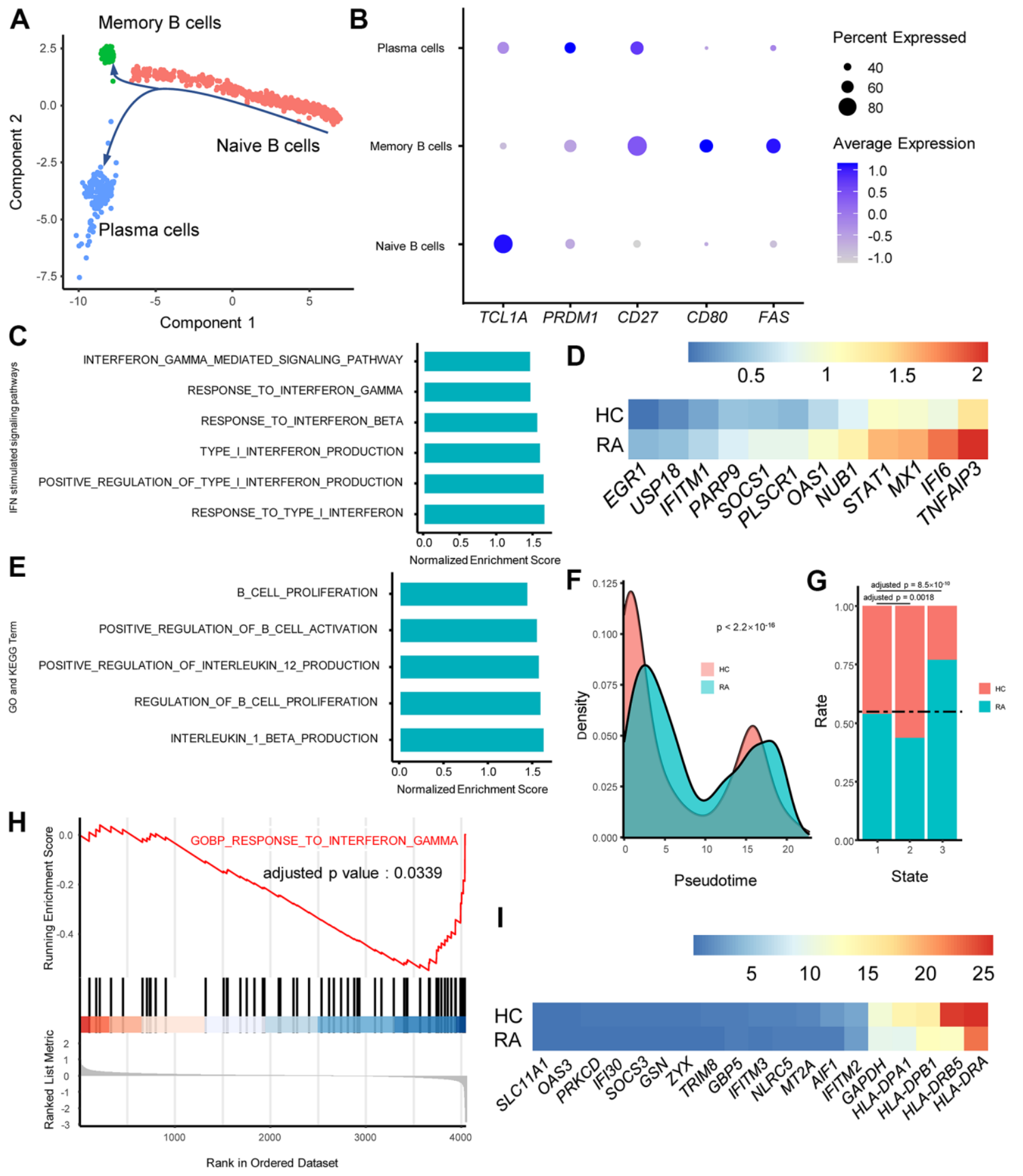

Figure 6. IFN alters rheumatoid arthritis (RA) B cell proliferation and activation and class switching in RA plasma cells. (A) Trajectory plots of T cells from RA and healthy control individuals (HC). The direction of arrows indicates the direction of pseudotime. (B) Dot plot illustrating the expression levels of several marker genes in three T cell subtypes. (C) Bar plots of selected gene set enrichment analysis (GSEA) results indicate activated IFN signaling pathways in RA naïve B cells. (D) Heat map of upregulated type I IFN stimulated genes in RA naïve $B$ cells. Genes are ordered according to their expression levels in RA naïve B cells. (E) GSEA results indicate activated B cell functions in RA naïve B cells. (F) Probability density plot of B cell pseudotimes in RA and HC. Pseudotimes between the RA patients and HCs were compared using the Mann-Whitney $U$ test. (G) Stacked bar plot of B cell subtype distribution in RA and HC. The horizontal dotted line indicates the overall B cell proportions in RA and HC. The proportions of memory B cells and plasma cells in the RA patient and HCs were compared to the proportions of naïve $B$ cells, and comparisons were performed using Fisher's exact test. (H) GSEA plot of the "GOBP_RESPONSE_TO_INTERFERON_GAMMA" pathway in RA plasma cells. (I) Heat map of downregulated IFN- $\gamma$-stimulated genes in RA plasma cells. Genes are ordered according to their expression levels in HC naïve B cells. 
stimulated genes and pathways in RA PBMCs. We first analyzed a microarray dataset including 232 RA PBMC samples and 43 HC PBMC samples, and the GSEA results demonstrated that the "GOBP RESPONSE_TO
TYPE_I_INTERFERON" and "GOBP_RESPONSE_TO INTERFERON_GAMMA" pathways were activated in $\overline{R A}$ (Supplementary Figure 2A, 2B), and related genes were also upregulated in RA (Supplementary Figure 2C,

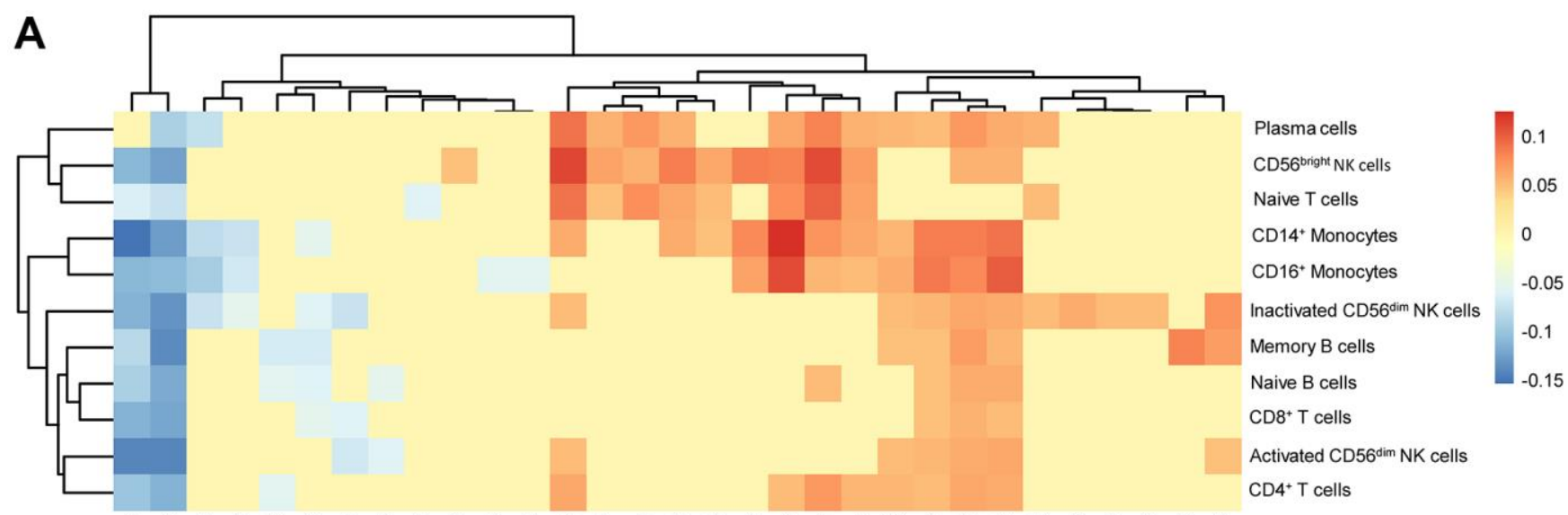

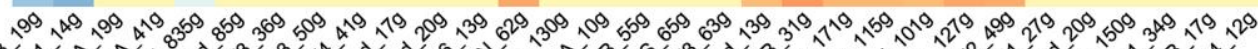
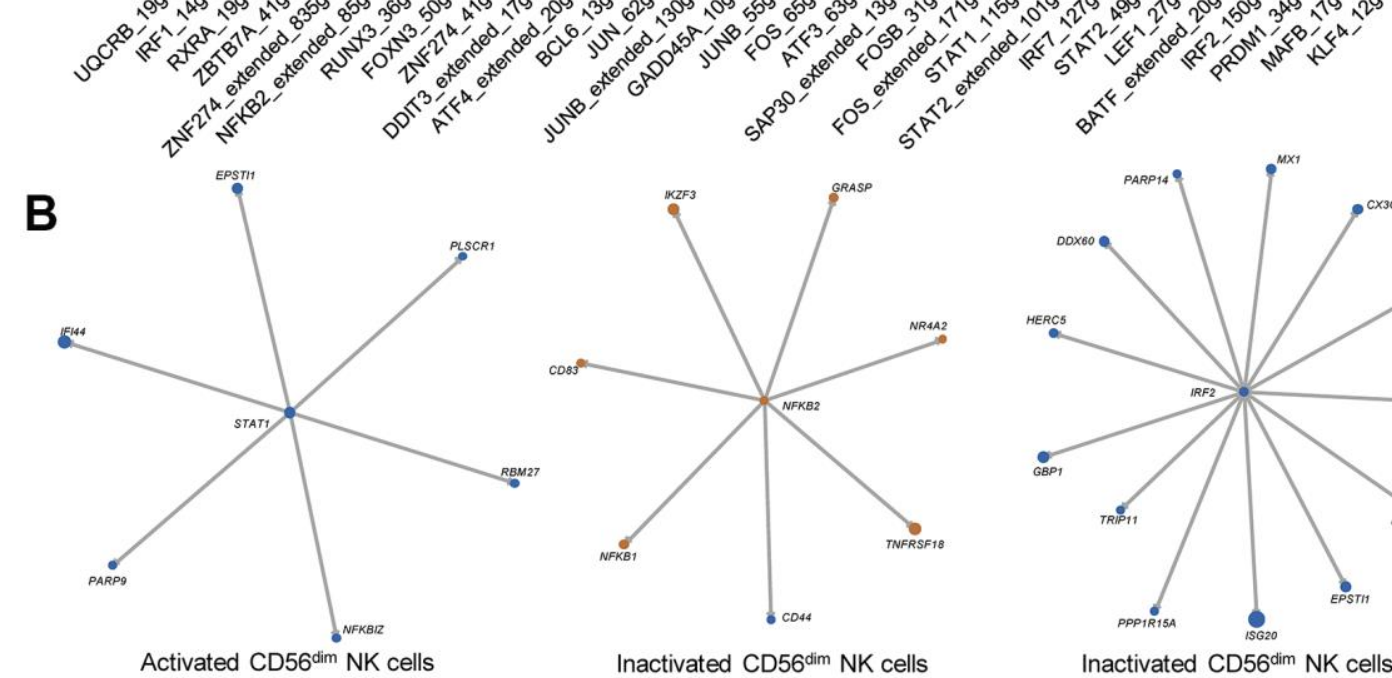

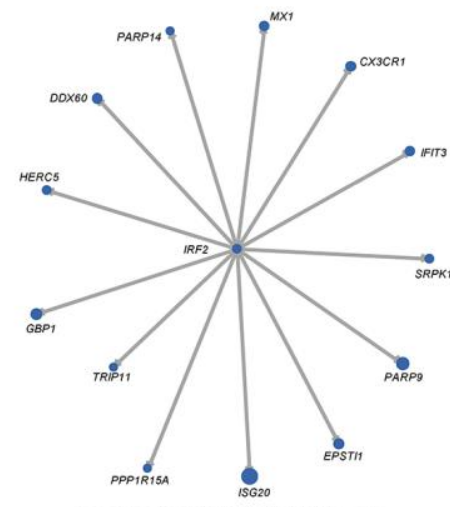

Inactivated CD56 dim NK cells

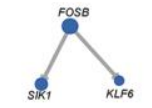

Naive B cells

KLF6

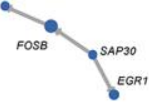

CD14+ Monocytes

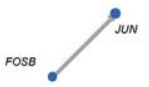

CD16 ${ }^{+}$Monocytes

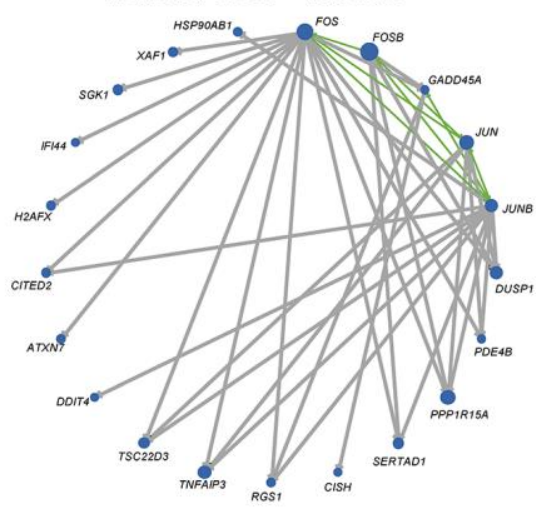

Naive T cells
Inactivated CD56 dim NK cells

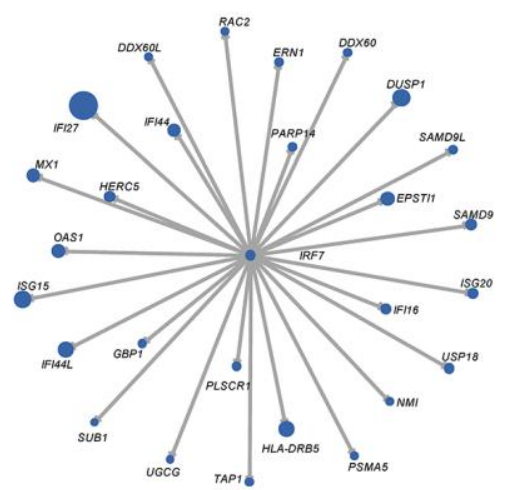

$\mathrm{CD}^{+} \mathrm{T}$ cells

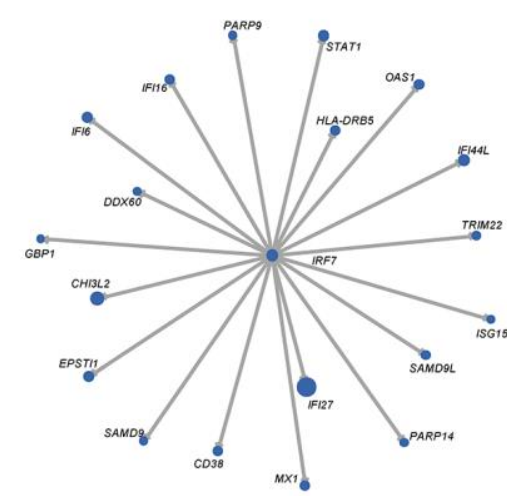

$\mathrm{CD8}^{+} \mathrm{T}$ cells

Figure 7. Key transcription factors and gene regulatory networks (GRNs) in each immune cell type from rheumatoid arthritis (RA) peripheral blood. (A) Heat map of differential regulons in each immune cell type. The heat map color indicates the difference in AUC values in RA patients and HCs, and only significantly different regulons are shown in the heat map. Red and blue indicated that the regulon is upregulated and downregulated in RA, respectively. (B) GRNs in each immune cell type. Blue and orange dots represent upregulated and downregulated genes in RA, respectively. The size of the dots corresponds to the absolute value of fold changes. Gray lines and green lines represent unidirectional and bidirectional regulatory relationships, respectively. 
2D). Furthermore, we investigated alterations in IFNstimulated pathways and genes in different cell types in RA PBMCs. The results indicated that the effects of type I IFN were primarily concentrated in $\mathrm{CD} 14^{+}$monocytes (Supplementary Figure 3), while the effects of IFN- $\gamma$ were primarily concentrated in monocytes, effector memory $\mathrm{CD}^{+}{ }^{+} \mathrm{T}$ cells and NK cells (Supplementary Figure 3 ). In addition, the GSEA results also suggested that NK cells in RA produced more IFN- $\gamma$ (Supplementary Figure 3), which is consistent with the results of scRNA sequencing analysis.

\section{DISCUSSION}

IFNs are a series of natural cytokines that exert pivotal immunomodulatory activities [37-39]. Both type I and II IFN are presumed to be the bridge between innate immune and adaptive immune responses due to their functions in enhanced antigen presentation. From this point, the intensities of type I and II IFN signaling pathways are crucial for the balance between selfreactivity and autoimmunity, illustrating that IFNs play important roles in autoimmune diseases.

Type I IFN can be produced by many immune cell types, including DCs, monocytes, and macrophages [13]. T cells and NK cells are the major producers of IFN- $\gamma$ [40]. Type I and II IFN can also act on immune cells in an autocrine fashion. The influences of IFN signaling on immune cells are comprehensive and involve multiple signaling pathways. The type I IFN receptor (IFNAR) activates its downstream target kinases, including JAK1 and TYK2, which promotes phosphorylation, dimerization, and nuclear translocation of STAT1 and STAT2 [41]. Finally, the expression of a series of genes called IFN-stimulated genes is facilitated. IFN- $\gamma$ also regulates gene expression by activating the JAK-STAT1 signaling pathway and other factors, including the AP-1, STAT3, STAT5, the MAP kinase signaling pathway, the PI3K signaling pathway and the NF- $\mathrm{KB}$ signaling pathway [42].

NK cells, T and B cells and monocytes are the crucial proportions of PBMCs, which are also involved in innate and acquired immune responses and are related to a series of autoimmune diseases. GSEA is a popular and useful tool to identify specific up- or downregulated pathways. In the present study, we determined that IFNrelated signaling pathways were activated in PBMCs from RA microarray data using GSEA and GO and KEGG pathways from the Molecular Signatures Database (MSigDB). Then we focused on the abnormal expression of type I and II IFN-related genes and gene sets, and consequent alterations in NK cells, monocytes, and $\mathrm{T}$ and $\mathrm{B}$ cells from RA peripheral blood.
$\mathrm{CD}^{\mathrm{dim}} \mathrm{NK}$ cells exert roles in the immune response primarily through there cytotoxic effects on abnormally activated $\mathrm{T}$ cells and macrophages, and CD56 $6^{\text {bright }} \mathrm{NK}$ cells primarily regulate the immune response by producing cytokines [43]. Aberrant alterations of NK cells partially contribute to the progression of RA. It has been reported that there are increased CD $56^{\text {bright }} \mathrm{NK}$ cells in inflamed synovial joints, which also express more IFN- $\gamma$ than NK cells in the peripheral blood [44]. Previous research also demonstrated that NK cell activity was impaired in RA [45].

NK cell activation relies on the stimulation of type I IFN [28]. In our study, we found that both type I IFNand IFN- $\gamma$-stimulated signaling pathways were activated in activated CD56 ${ }^{\mathrm{dim}} \mathrm{NK}$ cells and CD56 ${ }^{\text {bright }} \mathrm{NK}$ cells. Notably, in agreement with prior studies, our study also suggested decreased cytotoxic effects of RA activated and inactivated CD56 ${ }^{\mathrm{dim}} \mathrm{NK}$ cells [45].

It has been reported that NK cells stimulated with IFN- $\gamma$ exhibit increased phosphorylation of STAT1 or STAT4, and different activation of STATs leads to distinct NK cell phenotypes [28]. Specifically, STAT1 phosphorylation promotes the cytotoxic activity of NK cells, while STAT4 phosphorylation promotes NK cell cytokine secretion $[46,47]$. Although a higher level of STAT1 in RA-activated CD56 ${ }^{\mathrm{dim}}$ was detected, we speculated that the impaired NK cell activity in RA CD56 ${ }^{\text {dim }} \mathrm{NK}$ cells was related to IFN- $\gamma$ stimulation and downstream STAT4 phosphorylation.

Aberrant activation of monocytes also contributes to RA. CD14 ${ }^{+}$monocytes are more inclined to migrate to local tissues including joint cavities [29, 30]. A large number of peripheral $\mathrm{CD} 14^{+}$monocytes differentiate into osteoclasts in RA, ultimately leading to bone erosion. Herein, our study indicated that $\mathrm{CD} 14^{+}$ monocytes from RA exhibited increased HLA-DRB5 levels and IFN- $\gamma$ signaling pathway activation. $\mathrm{CD} 14^{+} \mathrm{CD} 16^{+} \mathrm{HLA}-\mathrm{DR}^{+}$monocytes secrete high levels of TNF, which indicates that HLA-DR ${ }^{+}$monocytes exhibit a potential proinflammatory phenotype [48]. IFN- $\gamma$ has been considered an effective inducer of HLADR expression on synovial monocytes by in vitro cell experiments [5]. Taken together with the above results, we speculate that higher expression of HLA-DR in $\mathrm{CD} 14^{+}$monocytes indicates stronger immune responses in RA peripheral blood.

$\mathrm{CD} 16^{+}$monocytes in RA also exert momentous effects on RA by producing proinflammatory cytokines, such as IL- $1 \beta$, IL-6, and TNF- $\alpha$ [5]. In our study, we found that RA CD $16^{+}$monocytes expressed more $\mathrm{CH} 25 \mathrm{H}$ than $\mathrm{HCs}$, accompanied by activation of the type I IFN signaling pathway. $\mathrm{CH} 25 \mathrm{H}$ is an enzyme that catalyzes 
the formation of 25-hydroxycholesterol $(25 \mathrm{HC})$ from cholesterol, and it has been demonstrated that $\mathrm{CH} 25 \mathrm{H}$ acts as an inflammatory signaling amplifier in macrophages [32, 49]. Moreover, individuals with higher $\mathrm{CH} 25 \mathrm{H}$ expression in synovial membranes are more likely to develop RA [50]. Previous research has demonstrated that $\mathrm{CH} 25 \mathrm{H}$ is an IFN-stimulated gene and that expression of $\mathrm{CH} 25 \mathrm{H}$ is induced by IFN- $\alpha$ [33]. Thus, we hypothesized that type I IFN promotes the expression of $\mathrm{CH} 25 \mathrm{H}$ in RA $\mathrm{CD}^{2} 6^{+}$monocytes, which aggravated the inflammatory response in RA $\mathrm{CD}_{16}{ }^{+}$monocytes. In addition, although expression of $\mathrm{CH} 25 \mathrm{H}$ represents an inflammatory signal, the relationship between $\mathrm{CH} 25 \mathrm{H}$ and RA needs further investigation because there are few relevant studies.

Consistently, $\mathrm{CD} 4^{+} \mathrm{T}$ cells occupy a core status in RA [51]. $\mathrm{CD}^{+} \mathrm{T}$ cells contain a $\mathrm{CD} 4^{+} \mathrm{T}$ cell subtype mixture of Th1, Th2, Th17, and regulatory $\mathrm{T}$ cells (Tregs). Among them, enhanced Th1 and Th17 activities, as well as elevated IFN- $\gamma$ and IL-17, promote inflammatory responses both in synovial membranes and in PBMCs [52]. Our study demonstrated that the IFN $-\gamma$ stimulated signaling pathway was activated in RA CD4 ${ }^{+} \mathrm{T}$ cells, indicating that it enhanced $\mathrm{CD} 4^{+} \mathrm{Th} 1$ polarization in RA. These results are consistent with previous studies [52]. $\mathrm{CD}^{+} \mathrm{T}$ cells also function in RA, but their precise roles in RA pathogenesis are still unclear [53]. Some animal studies have demonstrated that $\mathrm{CD}^{+} \mathrm{T}$ cells have proinflammatory effects via cytotoxicity [54]. However, other studies have indicated that $\mathrm{CD} 8^{+} \mathrm{T}$ cells play a regulatory role in inflamed joints [55]. In the present study, we found that $G Z M H$, a cytotoxic gene, was upregulated in $\mathrm{RA} \mathrm{CD} 8^{+} \mathrm{T}$ cells, supporting the view that the cytotoxicity of $\mathrm{CD} 8^{+} \mathrm{T}$ cells is enhanced in RA. It is also known that IFN- $\gamma$ can enhance the cytotoxicity of $\mathrm{CD} 8^{+} \mathrm{T}$ cells. Therefore, we hypothesized that the cytotoxicity of $\mathrm{CD} 8^{+} \mathrm{T}$ cells was elevated and was associated with the activation of IFN$\gamma$-stimulated pathways [34].

In RA, unnatural $B$ cell activation leads to the production of autoantibodies, including anti-cyclic citrullinated peptide (anti-CCP) and rheumatoid factor (RF). Unsurprisingly, we found that naïve B cells in RA exhibited stronger proliferation and activation, accompanied by the activation of activation of type I IFN. It has been previously demonstrated that type I IFN boosts $\mathrm{B}$ cell proliferation and differentiation to plasma cells [56]. EGR1, a type I IFN-stimulated gene, was also upregulated in RA naïve B cells [35]. Thus, we hypothesized that the activation of type I IFN partially enhanced B cell differentiation into plasma cells.

Activated $\mathrm{B}$ cells also regulate immune responses by secreting cytokines [36]. Both proinflammatory cytokines and anti-inflammatory cytokines can be produced by B cells, depending on the stimulus [57]. It has been reported that B cells from the autoimmune disease multiple sclerosis produce less of the antiinflammatory cytokine IL-10 [58]. Here, our study indicated that naïve B cells in RA had the potential to produce the proinflammatory cytokines IL- $1 \beta$ and IL12 , which might aggravate the inflammatory status in RA peripheral blood. Whether the cytokines from RA B cells are related to type I IFN and IFN- $\gamma$ activation remains to be further investigated.

Inhibition of the IFN- $\gamma$ signaling pathway in RA plasma cells is another interesting phenomenon observed in the present study. Previous studies have demonstrated that IFN- $\gamma$ intervenes in plasma cell isotype switch recombination by promoting $\mathrm{IgG} 2 \mathrm{a}$ production and inhibiting IgG1 production [59, 60]. Coincidentally, IgG1 and IgG4 are the primary subtypes of anti-CCPs in RA [61, 62]. As a result, we conjectured that the inhibited IFN- $\gamma$ signaling pathway in plasma cells might be associated with plasma cell isotype switch recombination in RA, which eventually promotes the production of autoantibodies.

Finally, IFN-regulated pathways and genes are complex and numerous. Therefore, we attempted to use SCENIC to evaluate the activity of each transcription factor and their target genes. We found that the activities of the regulons IRF7_127g, STAT1_115g, STAT2_49g, STAT2_extended_101g, IRF1_14g and UQCRB_19g were significantly increased or decreased in most cell types. There were several imbalanced transcription factors in RA, such as IRF1, IRF7, STAT1, and STAT2. They could be regulated by IFN, addressing the important IFN effects in RA [63-65]. Furthermore, we constructed GRNs by integrating the results of SCENIC analysis and DEG analysis in each cell type. Our GRNs might not be comprehensive due to the strict calculations of DEGs. Moreover, only a single RA sample with missing clinical characteristics was used in the main analysis of the present study, which limited the generalizability of the findings. Further research is required to explain the significance of these transcription factors in RA. Once their expression and functions are identified, these transcription factors could be used as potential targets in the treatment of RA due to their extensive influence instead of partial alterations in RA.

\section{CONCLUSIONS}

Knowledge of the relationship between IFN and RA is tortuous because IFN participates in multiple regulatory effects on the immune system [66]. Initially, type I IFN was used as a treatment option [67]. Subsequently, the 
promoting effects of IFN-stimulated signaling pathways on RA have been gradually recognized [68]. The type I IFN signature represents type I IFN response genes and pathways, that are activated in RA patients, which may play a role in the potential development of RA [11]. Meanwhile, contradictory findings indicated the dual effects of IFN- $\gamma$ on RA, and our findings demonstrated that IFN- $\gamma$-stimulated pathways were not always activated in all cell types in RA [69].

In the present study, we comprehensively analyzed the alterations of type I IFN- and IFN- $\gamma$-stimulated pathways in RA. Parts of the findings from the transcriptome analysis corroborate previous studies. The present study indicated that IFN signaling pathways are activated in RA patients, in agreement with prior investigations. A previous study showed that CD56 ${ }^{\mathrm{dim}}$ NK cells from RA patients are impaired, and our study supported that conclusion [45]. Enhanced Th1 activity and imbalanced Th1/Th2 cells in RA were detected very early [51]. Our research also found enhanced IFN- $\gamma$ signaling pathway in $\mathrm{RA} \mathrm{CD} 4^{+} \mathrm{T}$ cells, indicating that Th1 polarization is enhanced in $\mathrm{RA} \mathrm{CD} 4^{+}$helper T cells. However, the subtypes of $\mathrm{CD}^{+}$helper $\mathrm{T}$ cells are diverse, and the relationship between the Th17/Treg balance and RA has been observed in prior research [51]. How IFN signaling pathways and $\mathrm{CD}^{+}$helper T cell differentiation influence each other needs to be clearly demonstrated in future studies.

Our study also delivers some novel findings. We linked disease promotion of CD56 $6^{\text {bright }}$ and CD56 ${ }^{\mathrm{dim}} \mathrm{NK}$ cells in RA with activated IFN signaling pathways. Our research also indicated that the activated type I IFN signaling pathway might promote production of the inflammatory signaling amplifier $\mathrm{CH} 25 \mathrm{H}$. In addition, RA patient primary B cells tended to differentiate into plasma cells, and our investigation demonstrated that the type I IFN signaling pathway might be one of the factors causing this differentiation. Our analysis also demonstrated that the IFN- $\gamma$ signaling pathway in RA was activated, which might influence antibody class switching in RA plasma cells and autoantibody production. Finally, SCENIC was used to identify key transcription factors in different immune cells in RA, and GRNs were also constructed to reveal the mechanism of transcription regulation, which provides directions for future research on IFN signaling pathways in RA.

Although this study comprehensively explored the effects of abnormal type I and II IFN signaling pathways in RA PBMC immune cell subtypes, only one RA scRNA sample was used in our study, and the clinical characteristics of the RA patient were unknown. Thus, we suggest that further studies should focus on IFN-stimulated signaling pathways in RA using multiple samples and corresponding clinical information. Additionally, it is crucial to distinguish different INF signal alterations in distinct cell types to obtain a better cell classification performance, cell sorting is worth using before performing scRNA sequencing. Regardless, it is questionable whether IFN signaling pathways directly and/or indirectly promote the occurrence and development of RA according to previous studies. The relationship between IFN signaling pathways and RA immune cells should be carefully evaluated with a series of in vitro and in vivo experiments using a combination of novel sequencing technologies and traditional molecular biology techniques.

\section{MATERIALS AND METHODS}

\section{Acquisition of single-cell sequencing data and microarray data}

Both PBMC scRNA sequencing data and mRNA expression microarray data were downloaded from the Gene Expression Omnibus (GEO) database (https://www.ncbi.nlm.nih.gov/geo/). PBMC scRNA sequencing data of one RA patient and two HCs were obtained from GSE159117 and GSE149689, respectively $[70,71]$. The mRNA expression data of $232 \mathrm{RA}$ and $43 \mathrm{HC}$ PBMC samples, which were preprocessed by frozen robust multi-array analysis (fRMA) with batch effects corrected, were obtained from GSE93272 [72]. Microarray data preprocessed by fRMA of several immune cell subtypes in PBMCs were obtained from GSE93776 [72]. The design of this research is shown in Figure 1A.

\section{Data preprocessing and quality control}

For scRNA sequencing data, the $\mathrm{R}$ package Seurat (version 4.0.0) was used to preprocess the scRNA sequencing data [73-76]. First, cells were included if they met all three of the following parameters: (1) the number of genes in each cell was greater than 500; (2) the total number of molecules in a cell was greater than 1000 and less than 15000; and (3) the mitochondrial gene expression ratio was less than $5 \%$ and $15 \%$ for GSE159117 and GSE149689, respectively. Two GEO series scRNA data were normalized using "NormalizeData" function, and 3000 highly variable genes were identified using "FindVariableFeatures". Second, two GEO series were integrated in Seurat using the canonical correlation analysis (CCA) method with the "FindIntegrationAnchors" and "IntegrateData" functions.

Subsequently, the PCA method was performed for dimension reduction after data scaling, and the top 30 
principal components were selected to perform the downstream analysis. The UMAP algorithm was used to visualize and explore the data. Cell clusters were identified by the function "FindNeighbors" using the Knearest neighbors (KNN) algorithm and the function "FindClusters" with a resolution of 1.25.

\section{Cell class identification}

We calculated marker genes to annotate cell clusters to specific immune cell types. The following marker genes were used for cell type annotation: $C D 3 D$, KLRF1, CD79A, CD68, LILRA4, CD1C, and TUBB1 [77-80]. Correspondence between marker genes and cell types is shown in Figure 1C. Considering that the numbers of $\mathrm{pDCs}, \mathrm{mDCs}$, and megakaryocytes were too small, they were excluded from all subsequent analyses.

\section{Single-cell trajectory analysis and cell subtype identification}

To estimate the dissimilar functions of the different immune cell types in detail, the four main classes of immune cells (NK cells, monocytes, $\mathrm{T}$ cells, and B cells) were further divided according to the general classification criterion and certain marker genes. NK cells identified above were chosen, and reclustering was performed in Seurat using the same pipeline as previously described. NK cells were then subdivided into three clusters, and the following genes were used for NK cell subtype annotation: PRF1, GZMA, $G Z M B, G N L Y$ (activated CD56 ${ }^{\mathrm{dim}}$ NK cells), GZMH (inactivated CD56 ${ }^{\mathrm{dim}} \mathrm{NK}$ cells), and GZMK and SELL (CD56 ${ }^{\text {bright }}$ NK cells) $[81,82]$. For monocytes, T cells and $\mathrm{B}$ cells, the $\mathrm{R}$ package monocle (version 2.18.0) was used to perform single-cell trajectory analysis, and pseudotime trajectories were constructed using the DDRTree algorithm [83]. Subsequent genes were used for cell subtype identification: CD14 (CD14 monocytes), FCGR3A (CD16 ${ }^{+}$monocytes), CCR7, SELL (naïve $\mathrm{T}$ cells), CD4 $\left(\mathrm{CD}^{+}{ }^{+} \mathrm{T}\right.$ cells), CD8A $\left(\mathrm{CD}^{+} \mathrm{T}\right.$ cells), TCL1A (naïve $\mathrm{B}$ cells), PRDM1 (plasma cells), FAS, CD80 and CD27(memory B cells) [78, 84-86].

\section{Differentially expressed gene identification}

DEGs between cells from two individuals are important for determining their potential distinct biological functions. To identify DEGs between RA and $\mathrm{HC}$ in different immune cell subtypes, we used the FindMarkers function in Seurat to evaluate them and set min.pct $=0.1, \quad$ logfc.threshold $=0.25$, only.pos $=$ FALSE, and only genes with adjusted p-value $<0.05$ were retained.

\section{Gene set enrichment analysis}

GSEA was performed using the $\mathrm{R}$ package clusterprofiler (version: 3.18.1) [87]. Gene set files were downloaded from http://www.gsea-msigdb.org/gsea/ downloads.jsp, and all GO gene sets and KEGG gene sets were used for enrichment analysis. For scRNA sequencing data, genes were ranked using the "FindMarkers" function in Seurat. For microarray data, gene $\log 2$ (fold-change) values were calculated using the $\mathrm{R}$ package limma (version: 3.46.0), and all genes were decreasingly ranked by their $\log 2$ (fold-change) values [88]. The normalized enrichment score (NES) was used to assess the results of gene set enrichment. Pathways with an adjusted $\mathrm{p}$-value $<0.05$ and $|\mathrm{NES}|>1$ were considered significant. GSEA plots were created using the $\mathrm{R}$ package enrichplot (https://yulabsmu.top/biomedical-knowledge-mining-book/, version: 1.10.2). Bar plots were generated using the $\mathrm{R}$ package ggpubr (https://CRAN.R-project.org/package=ggpubr, version: 0.4.0).

\section{Single-cell regulatory network inference and clustering analysis and regulatory network construction}

SCENIC is a computational method to infer GRNs from single-cell RNA-seq data [89]. SCENIC analysis was performed according to the official workflow. We used the R package SCENIC (version: 1.2.4) and the GRNboost 2 algorithm in the python package arboreto (version: 0.1.5) to assess the gene regulatory relationships in subclasses of PBMCs [90]. Genes that were expressed at either very low levels or in too few cells were removed first; subsequently, we split the targets into positive- and negative-correlated targets by calculating the correlation in R. Gene coexpression networks were then constructed using the GRNboost2 algorithm in Python and SCENIC in R. AUC values of the regulon were calculated to measure the activity of the regulon. A heat map of regulon AUC values in each cell type was illustrated and clustered using $\mathrm{R}$ the package pheatmap (version: 1.0.12). Finally, the AUC values of the regulon in each subclass cell were compared using the limma package between the RA patients and HCs. Only a regulon with a $\operatorname{logFC} \geq 0.05$ and adjusted p-value $<0.05$ was considered significantly different between RA and HC groups. Finally, genes belonging to both different regulons between RA and $\mathrm{HC}$ and DEGs identified using the FindMarkers function were used for GRN construction.

\section{Statistical analysis}

We compared B cell pseudotime between RA and $\mathrm{HC}$ by using Mann-Whitney $\mathrm{U}$ test by function 
"wilcox.test" in R. Differences in B cell subtype proportions were compared using Fisher's exact test using the function "pairwise.fisher.test" in the R package fmsb (https://CRAN.R-project.org/package=

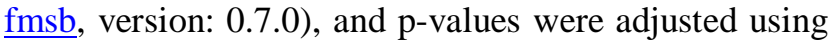
a Benjamini-Hochberg (BH) method. A p-value $<0.05$ was considered significant.

\section{Data availability}

Publicly available datasets were analyzed in this study. This data can be found here: https://www.ncbi.nlm.nih. gov/geo/query/acc.cgi?acc=GSE159117; https://www. ncbi.nlm.nih.gov/geo/query/acc.cgi?acc=GSE149689; https://www.ncbi.nlm.nih.gov/geo/query/acc.cgi?acc $=\mathrm{G}$ SE93272; https://www.ncbi.nlm.nih.gov/geo/query/acc. cgi?acc $=$ GSE93776.

\section{Abbreviations}

DCs: dendritic cells; IFNs: interferons; SLE: systemic lupus erythematosus; pSS: primary Sjögren syndrome; IL: interleukin; TNF: tumor necrosis factor; CIA : collagen-induced arthritis; scRNA: single cell RNA; PCA: principal component analysis; UMAP: uniform manifold approximation and projection; pDCs: plasmacytoid DCs; mDCs: myeloid DCs; GSEA: gene set enrichment analysis; HC: healthy control individuals; GO: Gene Ontology; BP: biological process; DEGs: differentially expressed genes; KEGG: Kyoto Encyclopedia of Genes and Genomes; SCENIC: Single-Cell rEgulatory Network Inference and Clustering; GRNs: gene regulatory networks; IFNAR: type I IFN receptor; 25HC: 25-hydroxycholesterol; Treg: regulatory $\mathrm{T}$ cells; anti-CCP: anti-cyclic citrullinated peptide; RF: rheumatoid factor; GEO: Gene Expression Omnibus; fRMA: frozen Robust Multi-array Analysis; CCA: canonical correlation analysis; KNN: K-nearest neighbors; NES: normalized enrichment score; BH: Benjamini-Hochberg.

\section{AUTHOR CONTRIBUTIONS}

SHT, ZC, and LH contributed to the conception and design of the study. LH analyzed the data, PS helped interpret the analysis results, $\mathrm{PS}, \mathrm{JHY}, \mathrm{YaoH}$, and $\mathrm{XB}$ searched and summarized related literatures. HHL and KY guided the scRNA sequencing data analysis. LH wrote the manuscript, TTL, WJL, YingH, KQ and YW revised the manuscript.

\section{CONFLICTS OF INTEREST}

The authors declare that the research was conducted in the absence of any commercial or financial relationships that could be construed as a potential conflict of interest.

\section{FUNDING}

This study was supported by the National Natural Science Foundation of China (81874383, 82074267) and the Chinese Medicine Scientific Research Project of the Health Commission of Hubei Province (ZY2021Q024).

\section{REFERENCES}

1. Guo Q, Wang Y, Xu D, Nossent J, Pavlos NJ, Xu J. Rheumatoid arthritis: pathological mechanisms and modern pharmacologic therapies. Bone Res. 2018; 6:15. https://doi.org/10.1038/s41413-018-0016-9 PMID:29736302

2. Yap HY, Tee SZ, Wong MM, Chow SK, Peh SC, Teow SY. Pathogenic Role of Immune Cells in Rheumatoid Arthritis: Implications in Clinical Treatment and Biomarker Development. Cells. 2018; 7:161.

https://doi.org/10.3390/cells7100161

PMID:30304822

3. Mateen S, Zafar A, Moin S, Khan AQ, Zubair S. Understanding the role of cytokines in the pathogenesis of rheumatoid arthritis. Clin Chim Acta. 2016; 455:161-71.

https://doi.org/10.1016/j.cca.2016.02.010

PMID:26883280

4. Bugatti S, Vitolo B, Caporali R, Montecucco C, Manzo A. $B$ cells in rheumatoid arthritis: from pathogenic players to disease biomarkers. Biomed Res Int. 2014; 2014:681678. https://doi.org/10.1155/2014/681678 PMID:24877127

5. Rana AK, Li Y, Dang Q, Yang F. Monocytes in rheumatoid arthritis: Circulating precursors of macrophages and osteoclasts and, their heterogeneity and plasticity role in RA pathogenesis. Int Immunopharmacol. 2018; 65:348-59. https://doi.org/10.1016/j.intimp.2018.10.016 PMID:30366278

6. Shegarfi H, Naddafi F, Mirshafiey A. Natural killer cells and their role in rheumatoid arthritis: friend or foe? ScientificWorldJournal. 2012; 2012:491974. https://doi.org/10.1100/2012/491974 PMID:22547986

7. $\mathrm{Yu} M B$, Langridge $\mathrm{WH}$. The function of myeloid dendritic cells in rheumatoid arthritis. Rheumatol Int. 2017; 37:1043-51. https://doi.org/10.1007/s00296-017-3671-z PMID:28236220

8. Shibabaw T, Molla MD, Teferi B, Ayelign B. Role of IFN and Complements System: Innate Immunity in SARSCoV-2. J Inflamm Res. 2020; 13:507-18. https://doi.org/10.2147/JIR.S267280 PMID:32982366 
9. Negishi $\mathrm{H}$, Taniguchi $\mathrm{T}$, Yanai $\mathrm{H}$. The Interferon (IFN) Class of Cytokines and the IFN Regulatory Factor (IRF) Transcription Factor Family. Cold Spring Harb Perspect Biol. 2018; 10:a028423.

https://doi.org/10.1101/cshperspect.a028423

PMID:28963109

10. Murira A, Lamarre A. Type-I Interferon Responses: From Friend to Foe in the Battle against Chronic Viral Infection. Front Immunol. 2016; 7:609.

https://doi.org/10.3389/fimmu.2016.00609 PMID:28066419

11. Lübbers J, Brink $M$, van de Stadt LA, Vosslamber $S$, Wesseling JG, van Schaardenburg D, RantapääDahlqvist S, Verweij CL. The type I IFN signature as a biomarker of preclinical rheumatoid arthritis. Ann Rheum Dis. 2013; 72:776-80.

https://doi.org/10.1136/annrheumdis-2012-202753 PMID:23434571

12. Dolhain RJ, ter Haar NT, Hoefakker S, Tak PP, de Ley M, Claassen E, Breedveld FC, Miltenburg AM. Increased expression of interferon (IFN)-gamma together with IFN-gamma receptor in the rheumatoid synovial membrane compared with synovium of patients with osteoarthritis. Br J Rheumatol. 1996; 35:24-32.

https://doi.org/10.1093/rheumatology/35.1.24 PMID: 8624619

13. Muskardin TL, Niewold TB. Type I interferon in rheumatic diseases. Nat Rev Rheumatol. 2018; 14:214-28.

https://doi.org/10.1038/nrrheum.2018.31

PMID:29559718

14. Travar M, Petkovic M, Verhaz A. Type I, II, and III Interferons: Regulating Immunity to Mycobacterium tuberculosis Infection. Arch Immunol Ther Exp (Warsz). 2016; 64:19-31.

https://doi.org/10.1007/s00005-015-0365-7 PMID:26362801

15. De Andrea M, Ravera R, Gioia D, Gariglio M, Landolfo S. The interferon system: an overview. Eur J Paediatr Neurol. 2002; 6:A41-46.

https://doi.org/10.1053/ejpn.2002.0573 PMID: 12365360

16. Zhou JH, Wang YN, Chang QY, Ma P, Hu Y, Cao X. Type III Interferons in Viral Infection and Antiviral Immunity. Cell Physiol Biochem. 2018; 51:173-85. https://doi.org/10.1159/000495172 PMID:30439714

17. Passos de Souza E, Evangelista Segundo PT, José FF, Lemaire D, Santiago M. Rheumatoid arthritis induced by alpha-interferon therapy. Clin Rheumatol. 2001; 20:297-99.

https://doi.org/10.1007/pl00011206

PMID:11529644
18. Kötter I, Müller CA, Einsele H, Mohren M, Kanz L. [Interferon-alpha-associated polyarthritis. Possible induction of seropositive rheumatoid arthritis by interferon-alpha: two case reports and review of the literature]. Z Rheumatol. 1999; 58:185-95.

https://doi.org/10.1007/s003930050169

PMID: 10502017

19. Higgs BW, Liu Z, White B, Zhu W, White WI, Morehouse C, Brohawn P, Kiener PA, Richman L, Fiorentino D, Greenberg SA, Jallal B, Yao Y. Patients with systemic lupus erythematosus, myositis, rheumatoid arthritis and scleroderma share activation of a common type I interferon pathway. Ann Rheum Dis. 2011; 70:2029-36.

https://doi.org/10.1136/ard.2011.150326

PMID:21803750

20. Roelofs MF, Wenink MH, Brentano F, AbdollahiRoodsaz S, Oppers-Walgreen B, Barrera P, van Riel PL, Joosten LA, Kyburz D, van den Berg WB, Radstake TR. Type I interferons might form the link between Toll-like receptor (TLR) 3/7 and TLR4-mediated synovial inflammation in rheumatoid arthritis (RA). Ann Rheum Dis. 2009; 68:1486-93.

https://doi.org/10.1136/ard.2007.086421 PMID: 18765427

21. Coclet-Ninin J, Dayer JM, Burger D. Interferon-beta not only inhibits interleukin-1beta and tumor necrosis factor-alpha but stimulates interleukin-1 receptor antagonist production in human peripheral blood mononuclear cells. Eur Cytokine Netw. 1997; 8:345-49. PMID: 9459613

22. Triantaphyllopoulos KA, Williams RO, Tailor $H$, Chernajovsky Y. Amelioration of collagen-induced arthritis and suppression of interferon-gamma, interleukin-12, and tumor necrosis factor alpha production by interferon-beta gene therapy. Arthritis Rheum. 1999; 42:90-99.

https://doi.org/10.1002/15290131(199901)42:1<90::AID-ANR12>3.0.CO;2-A PMID: 9920019

23. van Holten J, Pavelka K, Vencovsky J, Stahl H, Rozman B, Genovese M, Kivitz AJ, Alvaro J, Nuki G, Furst DE, Herrero-Beaumont G, Mclnnes IB, Musikic P, Tak PP. A multicentre, randomised, double blind, placebo controlled phase II study of subcutaneous interferon beta-1a in the treatment of patients with active rheumatoid arthritis. Ann Rheum Dis. 2005; 64:64-69. https://doi.org/10.1136/ard.2003.020347 PMID:15242865

24. Stark R, Grzelak M, Hadfield J. RNA sequencing: the teenage years. Nat Rev Genet. 2019; 20:631-56. https://doi.org/10.1038/s41576-019-0150-2 PMID:31341269 
25. Svensson V, Vento-Tormo R, Teichmann SA. Exponential scaling of single-cell RNA-seq in the past decade. Nat Protoc. 2018; 13:599-604.

https://doi.org/10.1038/nprot.2017.149

PMID:29494575

26. Stephenson W, Donlin LT, Butler A, Rozo C, Bracken B, Rashidfarrokhi A, Goodman SM, Ivashkiv LB, Bykerk VP, Orange DE, Darnell RB, Swerdlow HP, Satija R. Singlecell RNA-seq of rheumatoid arthritis synovial tissue using low-cost microfluidic instrumentation. Nat Commun. 2018; 9:791.

https://doi.org/10.1038/s41467-017-02659-x PMID:29476078

27. Zhang F, Wei K, Slowikowski K, Fonseka CY, Rao DA, Kelly S, Goodman SM, Tabechian D, Hughes LB, Salomon-Escoto K, Watts GF, Jonsson AH, RangelMoreno J, et al. and Accelerating Medicines Partnership Rheumatoid Arthritis and Systemic Lupus Erythematosus (AMP RA/SLE) Consortium. Defining inflammatory cell states in rheumatoid arthritis joint synovial tissues by integrating single-cell transcriptomics and mass cytometry. Nat Immunol. 2019; 20:928-42.

https://doi.org/10.1038/s41590-019-0378-1

PMID:31061532

28. Welsh RM. Natural killer cells and interferon. Crit Rev Immunol. 1984; 5:55-93.

PMID:6085941

29. Wong KL, Tai JJ, Wong WC, Han H, Sem X, Yeap WH, Kourilsky $\mathrm{P}$, Wong SC. Gene expression profiling reveals the defining features of the classical, intermediate, and nonclassical human monocyte subsets. Blood. 2011; 118:e16-31.

https://doi.org/10.1182/blood-2010-12-326355

PMID:21653326

30. Passos S, Carvalho LP, Costa RS, Campos TM, Novais FO, Magalhães A, Machado PR, Beiting D, Mosser D, Carvalho EM, Scott P. Intermediate monocytes contribute to pathologic immune response in Leishmania braziliensis infections. J Infect Dis. 2015; 211:274-82.

https://doi.org/10.1093/infdis/jiu439

PMID:25139016

31. Lari R, Kitchener PD, Hamilton JA. The proliferative human monocyte subpopulation contains osteoclast precursors. Arthritis Res Ther. 2009; 11:R23.

https://doi.org/10.1186/ar2616

PMID:19222861

32. Gold ES, Diercks AH, Podolsky I, Podyminogin RL, Askovich PS, Treuting PM, Aderem A. 25Hydroxycholesterol acts as an amplifier of inflammatory signaling. Proc Natl Acad Sci USA. 2014; 111:10666-71. https://doi.org/10.1073/pnas.1404271111 PMID:24994901

33. Liu SY, Aliyari R, Chikere K, Li G, Marsden MD, Smith JK, Pernet O, Guo H, Nusbaum R, Zack JA, Freiberg AN, Su $L$, Lee $B$, Cheng $G$. Interferon-inducible cholesterol-25hydroxylase broadly inhibits viral entry by production of 25-hydroxycholesterol. Immunity. 2013; 38:92-105. https://doi.org/10.1016/i.immuni.2012.11.005 PMID:23273844

34. Bhat $P$, Leggatt $G$, Waterhouse $N$, Frazer IH. Interferon$\checkmark$ derived from cytotoxic lymphocytes directly enhances their motility and cytotoxicity. Cell Death Dis. 2017; 8:e2836.

https://doi.org/10.1038/cddis.2017.67

PMID:28569770

35. Mora-López F, Pedreño-Horrillo N, Delgado-Pérez L, Brieva JA, Campos-Caro A. Transcription of PRDM1, the master regulator for plasma cell differentiation, depends on an SP1/SP3/EGR-1 GC-box. Eur J Immunol. 2008; 38:2316-24.

https://doi.org/10.1002/eji.200737861

PMID:18604866

36. Vazquez MI, Catalan-Dibene J, Zlotnik A. B cells responses and cytokine production are regulated by their immune microenvironment. Cytokine. 2015; 74:318-26.

https://doi.org/10.1016/j.cyto.2015.02.007 PMID:25742773

37. González-Navajas JM, Lee J, David M, Raz E. Immunomodulatory functions of type I interferons. Nat Rev Immunol. 2012; 12:125-35. https://doi.org/10.1038/nri3133 PMID:22222875

38. Li SF, Gong MJ, Zhao FR, Shao JJ, Xie YL, Zhang YG, Chang HY. Type I Interferons: Distinct Biological Activities and Current Applications for Viral Infection. Cell Physiol Biochem. 2018; 51:2377-96. https://doi.org/10.1159/000495897 PMID:30537741

39. Lee AJ, Ashkar AA. The Dual Nature of Type I and Type II Interferons. Front Immunol. 2018; 9:2061. https://doi.org/10.3389/fimmu.2018.02061 PMID:30254639

40. Resende $\mathrm{M}$, Cardoso MS, Ribeiro AR, Flórido M, Borges M, Castro AG, Alves NL, Cooper AM, Appelberg R. Innate IFN- $\gamma$-Producing Cells Developing in the Absence of IL-2 Receptor Common y-Chain. J Immunol. 2017; 199:1429-39.

https://doi.org/10.4049/jimmunol.1601701 PMID:28687660

41. Ivashkiv LB, Donlin LT. Regulation of type I interferon responses. Nat Rev Immunol. 2014; 14:36-49.

https://doi.org/10.1038/nri3581

PMID:24362405 
42. Tang $\mathrm{M}$, Tian L, Luo G, Yu X. Interferon-GammaMediated Osteoimmunology. Front Immunol. 2018; 9:1508.

https://doi.org/10.3389/fimmu.2018.01508 PMID:30008722

43. Björkström NK, Riese $P$, Heuts $F$, Andersson $S$, Fauriat C, Ivarsson MA, Björklund AT, Flodström-Tullberg M, Michaëlsson J, Rottenberg ME, Guzmán CA, Ljunggren HG, Malmberg KJ. Expression patterns of NKG2A, KIR, and CD57 define a process of CD56dim NK-cell differentiation uncoupled from NK-cell education. Blood. 2010; 116:3853-64.

https://doi.org/10.1182/blood-2010-04-281675 PMID:20696944

44. Dalbeth N, Callan MF. A subset of natural killer cells is greatly expanded within inflamed joints. Arthritis Rheum. 2002; 46:1763-72.

https://doi.org/10.1002/art.10410 PMID:12124859

45. Aramaki $\mathrm{T}$, Ida $\mathrm{H}$, Izumi $\mathrm{Y}$, Fujikawa $\mathrm{K}$, Huang $\mathrm{M}$, Arima K, Tamai M, Kamachi M, Nakamura H, Kawakami A, Origuchi T, Matsuoka N, Eguchi K. A significantly impaired natural killer cell activity due to a low activity on a per-cell basis in rheumatoid arthritis. Mod Rheumatol. 2009; 19:245-52.

https://doi.org/10.1007/s10165-009-0160-6

PMID:19283441

46. Nguyen KB, Cousens LP, Doughty LA, Pien GC, Durbin $\mathrm{JE}$, Biron CA. Interferon alpha/beta-mediated inhibition and promotion of interferon gamma: STAT1 resolves a paradox. Nat Immunol. 2000; 1:70-76.

https://doi.org/10.1038/76940

PMID:10881178

47. Nguyen KB, Watford WT, Salomon R, Hofmann SR, Pien GC, Morinobu A, Gadina M, O'Shea JJ, Biron CA. Critical role for STAT4 activation by type 1 interferons in the interferon-gamma response to viral infection. Science. 2002; 297:2063-66.

https://doi.org/10.1126/science.1074900

PMID:12242445

48. Belge KU, Dayyani F, Horelt A, Siedlar M, Frankenberger $M$, Frankenberger B, Espevik T, ZieglerHeitbrock L. The proinflammatory CD14+CD16+DR++ monocytes are a major source of TNF. J Immunol. 2002; 168:3536-42.

https://doi.org/10.4049/jimmunol.168.7.3536

PMID:11907116

49. Lund EG, Kerr TA, Sakai J, Li WP, Russell DW. cDNA cloning of mouse and human cholesterol 25hydroxylases, polytopic membrane proteins that synthesize a potent oxysterol regulator of lipid metabolism. J Biol Chem. 1998; 273:34316-27.

https://doi.org/10.1074/jbc.273.51.34316

PMID: $\underline{952097}$
50. Perucha E, Melchiotti R, Bibby JA, Wu W, Frederiksen KS, Roberts CA, Hall Z, LeFriec G, Robertson KA, Lavender P, Gerwien JG, Taams LS, Griffin JL, et al. The cholesterol biosynthesis pathway regulates IL-10 expression in human Th1 cells. Nat Commun. 2019; 10:498.

https://doi.org/10.1038/s41467-019-08332-9

PMID:30700717

51. Cope AP, Schulze-Koops H, Aringer M. The central role of T cells in rheumatoid arthritis. Clin Exp Rheumatol. 2007; 25:S4-11.

PMID:17977483

52. Scarsi M, Zanotti C, Chiarini M, Imberti L, Piantoni S, Frassi $M$, Tincani A, Airò $P$. Reduction of peripheral blood T cells producing IFN- $\gamma$ and IL-17 after therapy with abatacept for rheumatoid arthritis. Clin Exp Rheumatol. 2014; 32:204-10.

PMID:24428959

53. Carvalheiro $\mathrm{H}$, da Silva JA, Souto-Carneiro MM. Potential roles for $\mathrm{CD} 8(+) \mathrm{T}$ cells in rheumatoid arthritis. Autoimmun Rev. 2013; 12:401-09. https://doi.org/10.1016/j.autrev.2012.07.011 PMID:22841983

54. Kiely PD, Thiru S, Oliveira DB. Inflammatory polyarthritis induced by mercuric chloride in the Brown Norway rat. Lab Invest. 1995; 73:284-93.

PMID:7637329

55. Tada Y, Ho A, Koh DR, Mak TW. Collagen-induced arthritis in CD4- or CD8-deficient mice: CD8+ T cells play a role in initiation and regulate recovery phase of collagen-induced arthritis. J Immunol. 1996; $156: 4520-26$.

PMID:ㅇ66829

56. Hamilton JA, Hsu HC, Mountz JD. Role of production of type I interferons by B cells in the mechanisms and pathogenesis of systemic lupus erythematosus. Discov Med. 2018; 25:21-29.

PMID:29466691

57. Duddy ME, Alter A, Bar-Or A. Distinct profiles of human $B$ cell effector cytokines: a role in immune regulation? J Immunol. 2004; 172:3422-27.

https://doi.org/10.4049/jimmunol.172.6.3422 PMID:15004141

58. Duddy $M$, Niino $M$, Adatia $F$, Hebert $S$, Freedman $M$, Atkins $\mathrm{H}$, Kim HJ, Bar-Or A. Distinct effector cytokine profiles of memory and naive human B cell subsets and implication in multiple sclerosis. J Immunol. 2007; 178:6092-99.

https://doi.org/10.4049/jimmunol.178.10.6092 PMID:17475834

59. Kawano Y, Noma T, Yata J. Regulation of human IgG subclass production by cytokines. IFN-gamma and IL-6 
act antagonistically in the induction of human IgG1 but additively in the induction of IgG2. J Immunol. 1994; 153:4948-58.

PMID:7963558

60. Finkelman FD, Katona IM, Mosmann TR, Coffman RL. IFN-gamma regulates the isotypes of Ig secreted during in vivo humoral immune responses. J Immunol. 1988; 140:1022-27.

PMID: $\underline{3125247}$

61. Engelmann R, Brandt J, Eggert M, Karberg K, Krause A, Neeck G, Mueller-Hilke B. IgG1 and IgG4 are the predominant subclasses among auto-antibodies against two citrullinated antigens in RA. Rheumatology (Oxford). 2008; 47:1489-92.

https://doi.org/10.1093/rheumatology/ken336 PMID:18703528

62. Chapuy-Regaud S, Nogueira L, Clavel C, Sebbag M, Vincent C, Serre G. IgG subclass distribution of the rheumatoid arthritis-specific autoantibodies to citrullinated fibrin. Clin Exp Immunol. 2005; 139:542-50.

https://doi.org/10.1111/j.1365-2249.2004.02708.x PMID:15730401

63. Bonelli M, Dalwigk K, Platzer A, Olmos Calvo I, Hayer S, Niederreiter B, Holinka J, Sevelda F, Pap T, Steiner G, Superti-Furga G, Smolen JS, Kiener HP, Karonitsch T. IRF1 is critical for the TNF-driven interferon response in rheumatoid fibroblast-like synoviocytes : JAKinibs suppress the interferon response in RA-FLSs. Exp Mol Med. 2019; 51:1-11.

https://doi.org/10.1038/s12276-019-0267-6

PMID:31285419

64. Kasperkovitz PV, Verbeet NL, Smeets TJ, van Rietschoten JG, Kraan MC, van der Pouw Kraan TC, Tak PP, Verweij CL. Activation of the STAT1 pathway in rheumatoid arthritis. Ann Rheum Dis. 2004; 63:233-39.

https://doi.org/10.1136/ard.2003.013276

PMID:14962955

65. Yokoyama-Kokuryo W, Yamazaki H, Takeuchi T, Amano K, Kikuchi J, Kondo T, Nakamura S, Sakai R, Hirano F, Nanki T, Koike R, Harigai M. Identification of molecules associated with response to abatacept in patients with rheumatoid arthritis. Arthritis Res Ther. 2020; 22:46.

https://doi.org/10.1186/s13075-020-2137-y

PMID:32164778

66. Rodríguez-Carrio J, Alperi-López M, López $\mathrm{P}$, BallinaGarcía FJ, Suárez A. Heterogeneity of the Type I Interferon Signature in Rheumatoid Arthritis: A Potential Limitation for Its Use As a Clinical Biomarker. Front Immunol. 2018; 8:2007. https://doi.org/10.3389/fimmu.2017.02007 PMID:29387065
67. van Holten J, Plater-Zyberk C, Tak PP. Interferon-beta for treatment of rheumatoid arthritis? Arthritis Res. 2002; 4:346-52. https://doi.org/10.1186/ar598 PMID:12453310

68. Castañeda-Delgado JE, Bastián-Hernandez Y, Macias-Segura N, Santiago-Algarra D, Castillo-Ortiz JD, Alemán-Navarro AL, Martínez-Tejada P, EncisoMoreno L, Garcia-De Lira Y, Olguín-Calderón D, Trouw LA, Ramos-Remus C, Enciso-Moreno JA. Type I Interferon Gene Response Is Increased in Early and Established Rheumatoid Arthritis and Correlates with Autoantibody Production. Front Immunol. 2017; 8:285.

https://doi.org/10.3389/fimmu.2017.00285 PMID:28373872

69. Kato M. New insights into IFN- $\gamma$ in rheumatoid arthritis: role in the era of JAK inhibitors. Immunol Med. 2020; 43:72-78.

https://doi.org/10.1080/25785826.2020.1751908 PMID:32338187

70. Zhang B, Zhang $Y$, Xiong L, Li Y, Zhang Y, Zhao J, Jiang $H$, Li C, Liu Y, Liu X, Liu H, Ping YF, Zhang QC, et al. CD127 imprints functional heterogeneity to diversify monocyte responses in human inflammatory diseases. bioRxiv. 2020; 2020:11.10.

https://doi.org/10.1101/2020.11.10.376277

PMID:33200127

71. Lee JS, Park S, Jeong HW, Ahn JY, Choi SJ, Lee H, Choi B, Nam SK, Sa M, Kwon JS, Jeong SJ, Lee HK, Park SH, et al. Immunophenotyping of COVID-19 and influenza highlights the role of type I interferons in development of severe COVID-19. Sci Immunol. 2020; 5:eabd1554. https://doi.org/10.1126/sciimmunol.abd1554 PMID:32651212

72. Tasaki S, Suzuki K, Kassai Y, Takeshita M, Murota A, Kondo Y, Ando T, Nakayama Y, Okuzono Y, Takiguchi M, Kurisu R, Miyazaki T, Yoshimoto K, et al. Multiomics monitoring of drug response in rheumatoid arthritis in pursuit of molecular remission. Nat Commun. 2018; 9:2755.

https://doi.org/10.1038/s41467-018-05044-4 PMID:30013029

73. Hao $Y$, Hao S, Andersen-Nissen E, Mauck WM 3rd, Zheng S, Butler A, Lee MJ, Wilk AJ, Darby C, Zager M, Hoffman P, Stoeckius M, Papalexi E, et al. Integrated analysis of multimodal single-cell data. Cell. 2021; 184:3573-87.e29.

https://doi.org/10.1016/j.cell.2021.04.048

PMID:34062119

74. Stuart T, Butler A, Hoffman P, Hafemeister C, Papalexi E, Mauck WM 3rd, Hao Y, Stoeckius M, Smibert P, Satija R. Comprehensive Integration of Single-Cell Data. Cell. 2019; 177:1888-902.e21. 
https://doi.org/10.1016/j.cell.2019.05.031

PMID:31178118

75. Butler A, Hoffman P, Smibert P, Papalexi E, Satija R. Integrating single-cell transcriptomic data across different conditions, technologies, and species. Nat Biotechnol. 2018; 36:411-20.

https://doi.org/10.1038/nbt.4096 PMID:29608179

76. Satija R, Farrell JA, Gennert D, Schier AF, Regev A. Spatial reconstruction of single-cell gene expression data. Nat Biotechnol. 2015; 33:495-502.

https://doi.org/10.1038/nbt.3192 PMID:25867923

77. Baran $Y$, Bercovich A, Sebe-Pedros A, Lubling $Y$, Giladi A, Chomsky E, Meir Z, Hoichman M, Lifshitz A, Tanay A. MetaCell: analysis of single-cell RNA-seq data using Knn graph partitions. Genome Biol. 2019; 20:206.

https://doi.org/10.1186/s13059-019-1812-2

PMID:31604482

78. Zhang JY, Wang XM, Xing $X, X u Z$, Zhang $C$, Song JW, Fan X, Xia P, Fu JL, Wang SY, Xu RN, Dai XP, Shi L, et al. Single-cell landscape of immunological responses in patients with COVID-19. Nat Immunol. 2020; 21:1107-18.

https://doi.org/10.1038/s41590-020-0762-x

PMID:32788748

79. Chistiakov DA, Killingsworth MC, Myasoedova VA, Orekhov AN, Bobryshev YV. CD68/macrosialin: not just a histochemical marker. Lab Invest. 2017; 97:4-13.

https://doi.org/10.1038/labinvest.2016.116

PMID:27869795

80. Fisher MH, Di Paola J. Genomics and transcriptomics of megakaryocytes and platelets: Implications for health and disease. Res Pract Thromb Haemost. 2018; 2:630-39.

https://doi.org/10.1002/rth2.12129

PMID:30349880

81. Sedelies KA, Sayers TJ, Edwards KM, Chen W, Pellicci DG, Godfrey DI, Trapani JA. Discordant regulation of granzyme $\mathrm{H}$ and granzyme $\mathrm{B}$ expression in human lymphocytes. J Biol Chem. 2004; 279:26581-87.

https://doi.org/10.1074/jbc.M312481200

PMID:15069086

82. Bratke K, Kuepper M, Bade B, Virchow JC Jr, Luttmann W. Differential expression of human granzymes A, B, and $\mathrm{K}$ in natural killer cells and during CD8+ $\mathrm{T}$ cell differentiation in peripheral blood. Eur J Immunol. 2005; 35:2608-16.

https://doi.org/10.1002/eji.200526122

PMID: 16106370
83. Trapnell C, Cacchiarelli D, Grimsby J, Pokharel P, Li S, Morse M, Lennon NJ, Livak KJ, Mikkelsen TS, Rinn JL. The dynamics and regulators of cell fate decisions are revealed by pseudotemporal ordering of single cells. Nat Biotechnol. 2014; 32:381-86. https://doi.org/10.1038/nbt.2859 PMID:24658644

84. Wen W, Su W, Tang H, Le W, Zhang X, Zheng Y, Liu X, Xie L, Li J, Ye J, Dong L, Cui X, Miao Y, et al. Immune cell profiling of COVID-19 patients in the recovery stage by single-cell sequencing. Cell Discov. 2020; 6:31. https://doi.org/10.1038/s41421-020-0168-9 PMID:32377375

85. Cattoretti G, Angelin-Duclos C, Shaknovich R, Zhou H, Wang D, Alobeid B. PRDM1/Blimp-1 is expressed in human B-lymphocytes committed to the plasma cell lineage. J Pathol. 2005; 206:76-86.

https://doi.org/10.1002/path.1752

PMID:15772984

86. Kurosaki T, Kometani K, Ise W. Memory B cells. Nat Rev Immunol. 2015; 15:149-59. https://doi.org/10.1038/nri3802 PMID:25677494

87. Yu G, Wang LG, Han Y, He QY. clusterProfiler: an R package for comparing biological themes among gene clusters. OMICS. 2012; 16:284-87.

https://doi.org/10.1089/omi.2011.0118 PMID:22455463

88. Ritchie ME, Phipson B, Wu D, Hu Y, Law CW, Shi W, Smyth GK. limma powers differential expression analyses for RNA-sequencing and microarray studies. Nucleic Acids Res. 2015; 43:e47. https://doi.org/10.1093/nar/gkv007 PMID:25605792

89. Aibar S, González-Blas CB, Moerman T, Huynh-Thu VA, Imrichova $H$, Hulselmans $G$, Rambow $F$, Marine JC, Geurts P, Aerts J, van den Oord J, Atak ZK, Wouters J, Aerts S. SCENIC: single-cell regulatory network inference and clustering. Nat Methods. 2017; 14:1083-86. https://doi.org/10.1038/nmeth.4463 PMID:28991892

90. Moerman T, Aibar Santos S, Bravo González-Blas C, Simm J, Moreau Y, Aerts J, Aerts S. GRNBoost2 and Arboreto: efficient and scalable inference of gene regulatory networks. Bioinformatics. 2019; 35:2159-61. https://doi.org/10.1093/bioinformatics/bty916 PMID:30445495 


\section{SUPPLEMENTARY MATERIALS}

\section{Supplementary Figures}

A

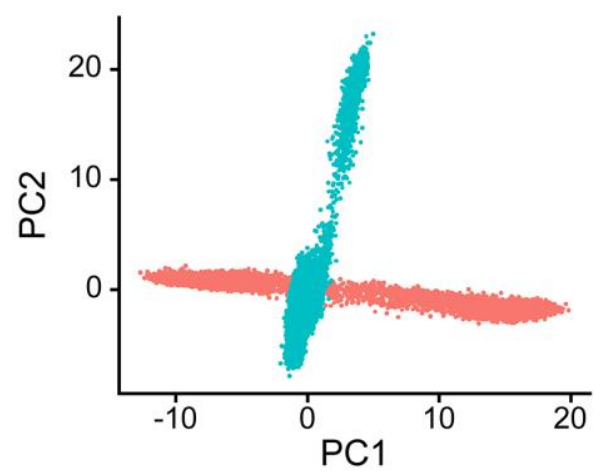

C

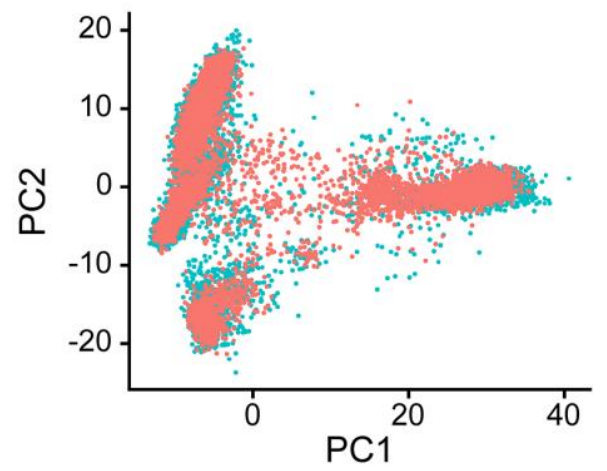

B

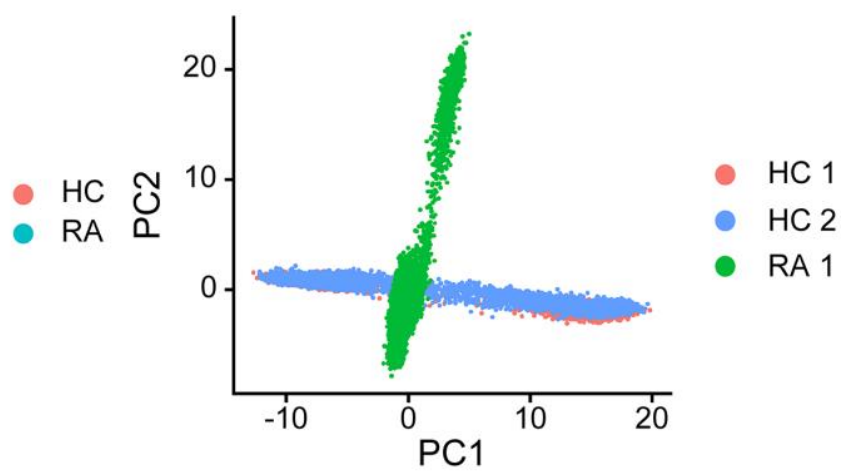

D

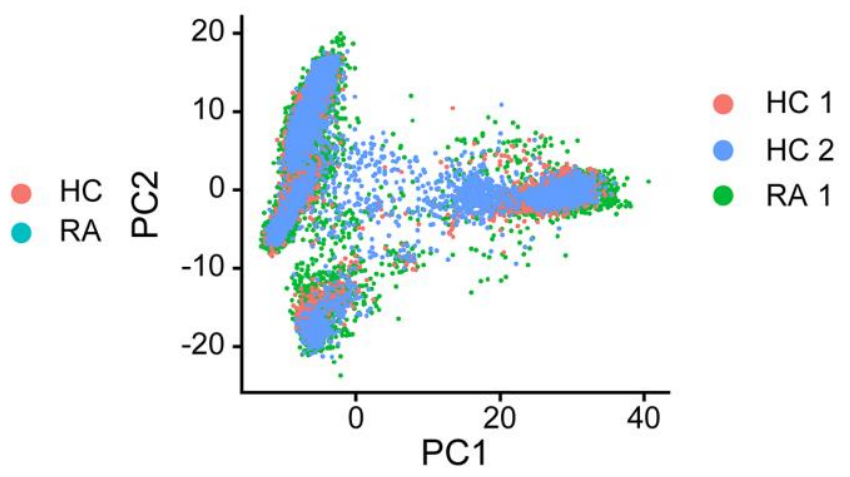

Supplementary Figure 1. Principal component analysis (PCA) visualization suggested that batch effects were removed between rheumatoid arthritis (RA) and healthy control individuals (HC) by canonical correlation analysis (CCA). (A) PCA visualization of cells before performing CCA, and cells are colored by batch. (B) PCA visualization of cells before performing CCA, and cells are colored by sample. (C) PCA visualization of cells after performing CCA, and cells are colored by batch. (D) PCA visualization of cells after performing CCA, and cells are colored by sample. PC: principal component. 


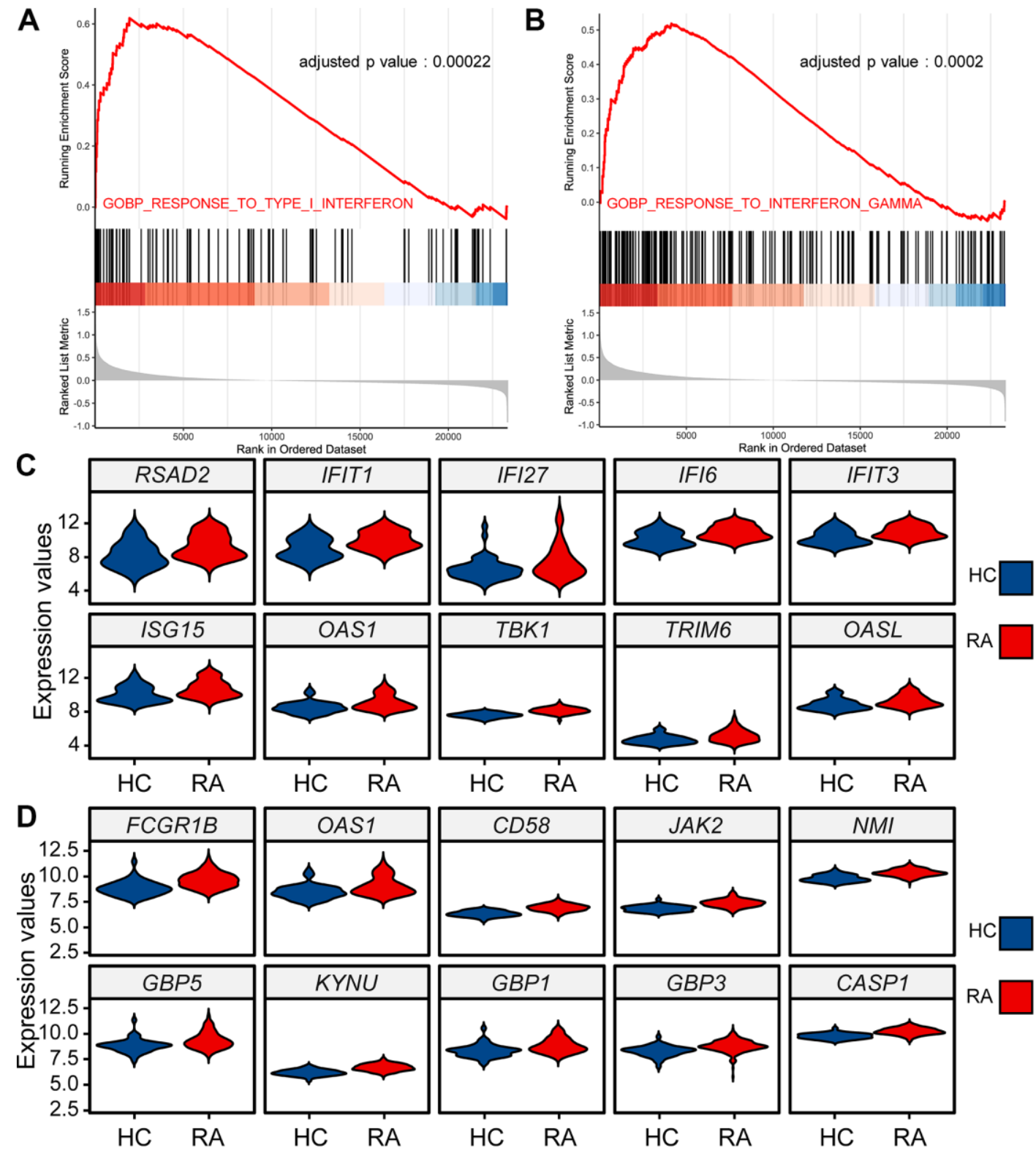

Supplementary Figure 2. Upregulated interferon (IFN)-stimulated signaling pathways and genes in rheumatoid arthritis (RA) peripheral blood. (A, B) Bar plots of selected results of GSE93272 gene set enrichment analysis (GSEA) indicated upregulated Type I IFN (A) and IFN- $\gamma$ (B) stimulated signaling pathways in RA. (C) Violin plots of the top 10 upregulated genes in the type I IFN-stimulated signaling pathway. (D) Violin plots of the top 10 upregulated genes in the IFN- $\psi$-stimulated signaling pathway. Genes in (C, D) are ordered according to fold changes, and only genes satisfying adjusted $p$-value $<0.05$ are shown. 


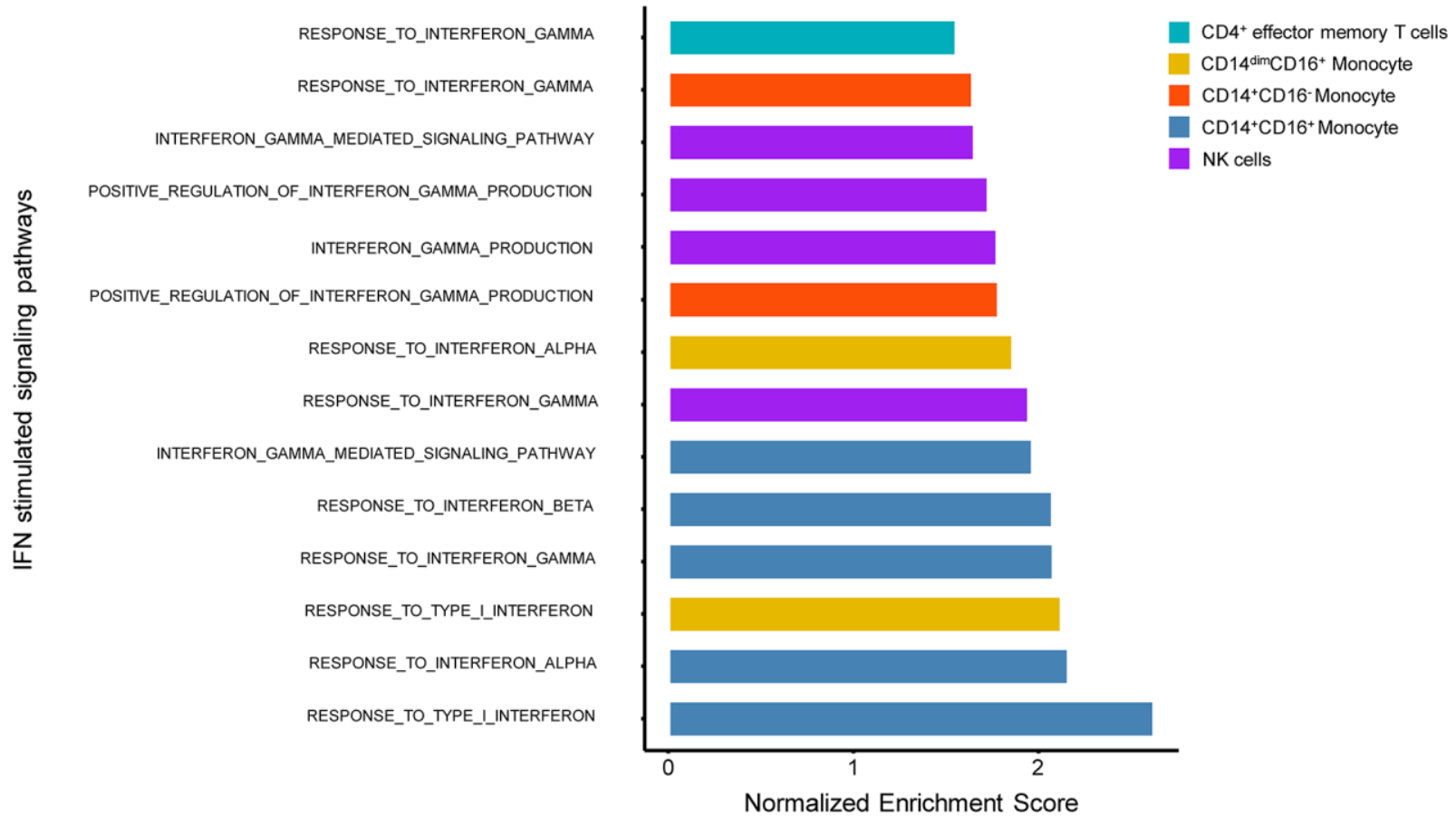

Supplementary Figure 3. Upregulated interferon (IFN)-stimulated signaling pathways in immune cells from rheumatoid arthritis (RA) peripheral blood. Bar plots of selected results of GSE93776 gene set enrichment analysis (GSEA) showing activated IFNstimulated signaling pathways in RA peripheral blood. The horizontal axis represents the normalized enrichment score. Adjusted p-values of all pathways satisfied were less than 0.05 . 